\title{
Action potential influences spatial perception: Evidence for genuine top-down effects on perception
}

\author{
Jessica K. Witt ${ }^{1}$
}

Published online: 23 November 2016

(C) Psychonomic Society, Inc. 2016

\begin{abstract}
The action-specific account of spatial perception asserts that a perceiver's ability to perform an action, such as hitting a softball or walking up a hill, impacts the visual perception of the target object. Although much evidence is consistent with this claim, the evidence has been challenged as to whether perception is truly impacted, as opposed to the responses themselves. These challenges have recently been organized as six pitfalls that provide a framework with which to evaluate the empirical evidence. Four case studies of actionspecific effects are offered as evidence that meets the framework's high bar, and thus that demonstrates genuine perceptual effects. That action influences spatial perception is evidence that perceptual and action-related processes are intricately and bidirectionally linked.
\end{abstract}

Keywords Embodied cognition $\cdot$ Spatial cognition $\cdot$ Visual perception $\cdot$ Action-specific perception

No vision scientist would deny that a primary purpose of vision is action. But how vision best serves action has been continuously debated. For some, visual perception best serves action by being as geometrically accurate as possible. Given ambiguities in the visual information, the visual system makes underlying assumptions (known as priors or natural constraints) and unconscious inferences based on statistical regularities of the environment. These approaches fall under constructivist accounts. Action's role in constructivist approaches is primarily limited to being a motivation for why

Jessica K. Witt

Jessica.Witt@ColoState.edu

1 Department of Psychology, Colorado State University, 241 Behavioral Sciences Building, Fort Collins, CO 80523, USA perception needs to achieve constancy (so that visual information can be successfully transformed into motor coordinates), but is not itself considered to be an influence for perception.

Even for approaches to vision that place a greater emphasis on action, its role is limited. According to the ecological account, perception best serves action by being faithful to the visual information, without being supplemented with extraneous ideas (Gibson, 1979; see Witt \& Riley, 2014, for extended discussion on the discrepencies between ecological and action-specific approaches). In situations in which the visual information is ambiguous, the perceiver can simply move around the object to accumulate more information until the information is unambiguous. For ecological accounts, action's role is relevant in gathering the necessary visual information, and action drives perception to actively select the information that is relevant for action, but action does not provide direct information for perception. As another example of an account that purportedly emphasizes action, the theory of two visual streams emphasizes both perception and action (Milner \& Goodale, 1995). However, even this theory divorces perception from action by considering the two to be subserved by anatomically different pathways. Indeed, such theories refer to the ventral pathway as "vision for perception" and the dorsal pathway as "vision for action." Given that the processing in the dorsal stream is thought to be unconscious (Milner \& Goodale, 2008), this theory emphasizes the role of action as being largely outside of conscious perceptual experience.

In contrast, the action-specific account of perception has argued that action plays a direct role in how the spatial properties of objects are consciously experienced. For example, softball players who are hitting better than others see the ball as bigger (Gray, 2013; Witt \& Proffitt, 2005). As another example, hills appear steeper and distances farther to observers who are fatigued, obese, or burdened by a heavy load (Bhalla \& Proffitt, 1999; Proffitt, Stefanucci, Banton, \& 
Epstein, 2003; Sugovic, Turk, \& Witt, 2016; Taylor-Covill \& Eves, 2013, 2014, 2016). According to this approach, a person's ability to perform the intended action influences the spatial perception of the target object.

The action-specific approach has been under intense scrutiny as to whether the empirical findings demonstrate genuine effects on spatial perception (Durgin et al., 2009; Firestone, 2013; Philbeck \& Witt, 2015; Proffitt \& Linkenauger, 2013; Witt, 2015; Witt \& Riley, 2014). The issue is that perception cannot be measured directly, and instead must be inferred on the basis of behavioral responses. These responses are also a function of the postperceptual processes involved in generating the response, and are prone to demand characteristics (Orne, 1682; Poulton, 1979). Thus, any particular effect could be due to differences in the initial percept, or instead to changes in postperceptual processes.

Determining whether or not action-specific effects are truly perceptual has important implications for theories of spatial vision, because they would demonstrate a top-down effect through which information related to action (typically thought of as the endpoint of cognitive processing; Rosenbaum, 2005) would influence perceptual processes (typically thought of as the starting point of cognitive processing). More broadly, a genuine top-down effect on perception would have theoretical consequences for the central question of how the mind works, because it would speak to the way the mind is organized (Firestone \& Scholl, in press-a). Actionspecific effects challenge the very notion that vision is its own module of the mind, and instead present evidence that it is intimately connected with the mental processes related to action. In contrast, if research were to demonstrate that actionspecific effects are not perceptual, the research would not challenge the claim of a modular division of labor, with perception being its own distinct, segregated process.

Concerns over whether a particular effect is indisputably perceptual have been raised throughout the history of research of perception. Some notable examples include whether crossmodal effects are truly perceptual (e.g., Shams \& Kim, 2010; Shimojo \& Shams, 2001) and whether certain tendencies (such as the specific-distance tendency; Gogel, 1969) and priors (such as the light-from-above prior; Ramachandran, 1988) are perceptual. As such, several strategies have been developed to address this fundamental question of the mind. Over the past decade, both concerns and strategies have been applied to the action-specific account of perception (for an extensive review, see Philbeck \& Witt, 2015).

Recently, these concerns and the corresponding strategies have been organized into six pitfalls, with the idea that if an effect of action ability falls at any of these pitfalls, this renders it illegitimate as a top-down perceptual effect (Firestone \& Scholl, in press-a). The six pitfalls are as follows. The first is to ensure that effects are present when they are theorized to occur, and also that they are absent when theory deems they should not occur. In other words, research should not be overly confirmatory, but should also provide evidence of unique disconfirmatory predictions. The second pitfall is to disentangle perception from judgments. The third is to ensure that effects are not due to demand characteristics or response biases, the fourth to ensure that they are not due to low-level visual differences, and the fifth to rule out any role of peripheral attentional effects. The sixth, and final, pitfall is to verify that effects are due to perception rather than memory.

These pitfalls provide a checklist to assess the authenticity of a purported top-down perceptual effect. Because the pitfalls were offered in the broader context of all top-down effects on perception, the framework has been applied only in bits and pieces to the action-specific literature, with studies being cherry-picked on the basis of which best exemplified a given pitfall. This strategy has been effective at illustrating how each pitfall can be applied, but it has been ineffective at proving that the entire field of action-specific perception fails to be genuinely perceptual. Many different types of action-specific effects have been demonstrated, and each one must be assessed. Proving that one particular effect, such as the backpack effect, is not perceptual does not mean that all other action-specific effects are also not perceptual.

There are asymmetries in the evidence that is needed to make a case that a particular effect is or is not perceptual. With respect to an individual effect, much more evidence is needed to prove that it is perceptual than that it is not. To claim that one particular action-specific effect is perceptual requires proof that none of the pitfalls can account for the effect. In contrast, evidence in favor of just one pitfall is sufficient to prove that the effect is not perceptual. However, with respect to the broader claim that action-specific effects can never be perceptual, more evidence may be needed. If one actionspecific effect passes the test of the pitfalls, this would indicate that action-specific effects can be (and that at least one is) perceptual (Firestone \& Scholl, in press-b; Witt, Sugovic, Tenhundfeld, \& King, in press). Proving that some actionspecific effects are not perceptual is insufficient to make claims about the field as a whole. Here, four types of actionspecific effects are evaluated under the six-pitfall framework. By meeting the standard set forth by this framework, the evidence speaks to genuine top-down influences of action on spatial perception.

\section{Case Study 1: Ball blocking performance affects perceived speed}

Many studies have shown a relationship between athletic performance and apparent target size. Softball players who are hitting better than others judge the ball to be bigger (Gray, 2013; Witt \& Proffitt, 2005). Archers shooting better than others judge the target to be bigger (Lee, Lee, Carello, \& 
Turvey, 2012); golfers playing better than others judge the hole to be bigger (Witt, Linkenauger, Bakdash, \& Proffitt, 2008); parkour athletes judge walls to be shorter than do novices (Taylor, Witt, \& Sugovic, 2011), and more skilled swimmers judge underwater targets to be closer than do less skilled swimmers (Witt, Schuck, \& Taylor, 2011). Because these studies were conducted in the field, it can be difficult to perfect the experimental design to account for all possible alternative explanations. For example, in the softball study, players judged ball size by selecting a circle from a range of differently sized circles presented on a posterboard that matched the size of the ball. They performed this task from memory, thus preventing researchers from knowing whether the correlation between estimated size and batting performance was due to an effect on perception or memory. In addition, the study relied on a correlation, and thus cannot speak to the direction of the effect. Perhaps the players who initially saw the ball as bigger were able to hit better. Indeed, evidence suggests that visual illusions that increase the perceived size of a target also improve subsequent performance (Chauvel, Wulf, \& Maquestiaux, 2015; Witt, Linkenauger, \& Proffitt, 2012; Wood, Vine, \& Wilson, 2013).

These concerns can be alleviated in certain circumstances. For example, in one experiment, we tested the perceived size of an American football field goal (Witt \& Dorsch, 2009). Participants estimated the goal size both before and after attempting ten kicks through the goal. This allowed us to dissociate the effects of performance on the perceptual reports from the effects of perception on performance. We found that the judged goal size was related to performance when the judgments were made after kicking but not before, suggesting that performance can affect perceptual judgments. In addition, the goal was within view as participants adjusted a miniature version of the goal that was used to assess perceived size. This result suggests an effect on perception rather than memory. However, other pitfalls could still apply.

Given the intensive testing necessary to evaluate all six pitfalls, a lab-based task is better suited to examining the effects of performance on perceptual judgments. Mila Sugovic and I developed such a task to follow up on the effect of performance in tennis on perceived ball speed (Witt \& Sugovic, 2010). In what has become known in my lab as the Pong paradigm, a ball bounces across a projection or computer screen, and participants use a joystick to control a paddle in an attempt to block the ball (see Fig. 1). We manipulated performance by varying the size of the paddle from trial to trial. After each attempt, participants estimated the speed of the ball. Our typical method of assessing perceived speed has been to use a speed-bisection task. In this task, which was modeled after traditional time bisection tasks, participants are initially trained on a slow anchor speed and a fast anchor speed. During test trials, participants judge each ball as having a speed more like the slow or more like the fast speed. From

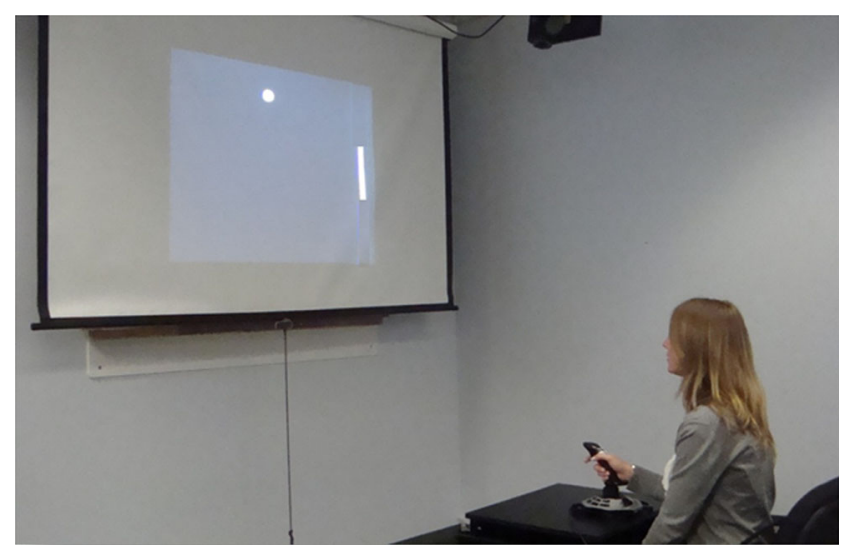

Fig. 1 A typical setup for the Pong experiment. Here the medium paddle is shown. In more recent studies, the experiment has been performed on a computer monitor rather than a projection screen

these data, the point of subjective equality (PSE) is determined for each paddle size and is the measure of perceived speed. Differences in the PSEs across paddle sizes are theorized to be due to the influence of ball-blocking performance on perceived speed (see Fig. 2). Other methods of assessing perceived speed, including a speed-rating judgment (rating the ball's speed on a scale of 1-7) and a visual matching task (indicating whether the ball moved faster or slower than a comparison circle), also showed effects of paddle size on the judged ball speed (Witt \& Sugovic, 2012).

All three measures showed the same pattern of results: The ball was judged to be moving faster when the paddle was small, and less effective at blocking the ball, than when the paddle was big. The visual information specifying ball speed

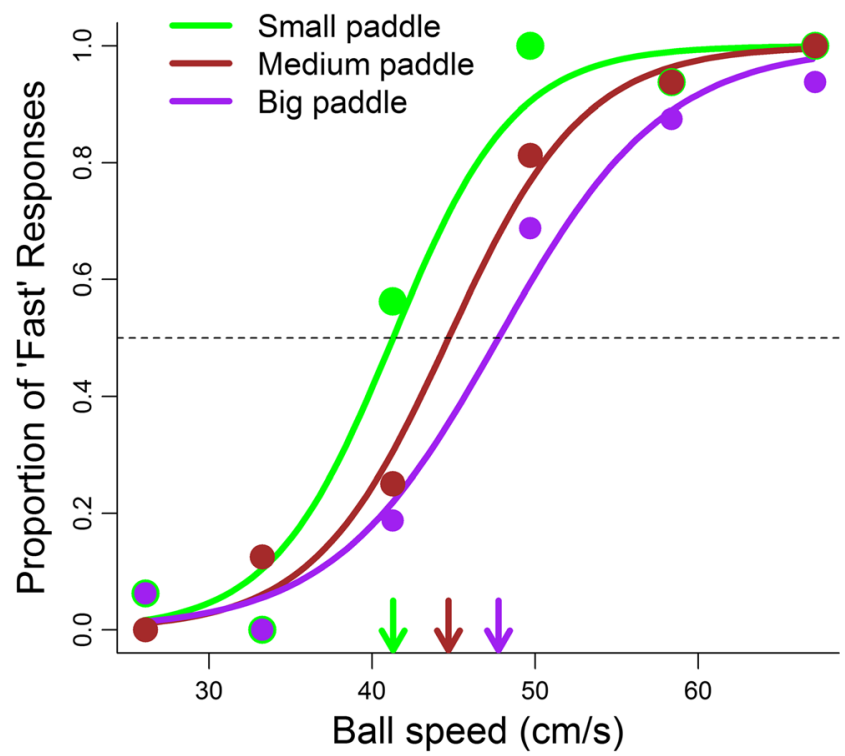

Fig. 2 Representative data from one participant: Mean proportions of responses that the ball's speed was more like the fast anchor speed, as a function of ball speed and paddle size. The curves represent logistic regressions for each paddle size, and the arrows represent the points of subjective equality for different paddle sizes. Note that a lower PSE corresponds to seeing the ball as moving faster 
was constant across the paddle size conditions, yet reports of ball speed differed depending on the ease with which the ball could be caught. But did people truly perceive the ball to be faster or slower? To evaluate this claim, the data were scrutinized using the six-pitfall framework.

\section{Pitfall \#1: Uniquely disconfirmatory predictions}

The checklist calls for research that shows null effects when the theory predicts null effects. Null effects can be difficult to publish, which leads to overly confirmatory research in the literature. But in the case of the effect of ball-blocking performance on apparent ball speed, several disconfirmatory effects have been reported. When paddle size is manipulated and affects ball-blocking performance, an effect on apparent speed is expected. Conversely, when paddle size is manipulated but does not affect ball-blocking performance, an effect on apparent speed is not expected. The latter scenario provides a unique disconfirmatory prediction.

In one study, the ball moved in a straight line across the display, so successful blocking performance only required that participants maintained the current location of the paddle. In this case, the paddle size had little effect on ball-blocking performance, and, as expected, paddle size also had little effect on the estimated ball speed (Witt \& Sugovic, 2012). In another study, the paddle was set to one of six sizes on each trial (rather than small, medium, and big sizes). Ball-blocking performance did not vary across the three largest-sized paddles, and, as expected, the speed estimates also did not vary across these paddle sizes (Witt \& Sugovic, 2012).

Uniquely disconfirmatory predictions have also been made when watching a computer play the game. When watching another human play, paddle size continues to influence the estimated ball speed (Witt, South, \& Sugovic, 2014; Witt, Sugovic, \& Taylor, 2012). When watching another person, the perceiver is theorized to simulate how the perceiver would do if placed in the actor's situation. But when observing a computer, motor simulation does not take place (Kilner, Paulignan, \& Blakemore, 2003). In one study, the computer's performance was perfect with all three paddle sizes. For participants who had not yet had experience playing the game themselves, paddle size did not affect the reported ball speed when they observed the computer play. In another study, the computer's performance was not perfect and corresponded to the paddle size. Again, the paddle size did not affect the apparent ball speed (Witt, Sugovic, \& Taylor, 2012). These four studies have revealed uniquely disconfirmatory predictions.

\section{Pitfall \#2: Perception versus judgment}

The second pitfall is to ensure that the purported effects are due to differences in perception, rather than to differences in the judgments used to assess perception. Unlike the straightforward recommendations from Pitfall \#1, distinguishing between perception and judgment can be immensely challenging, and the separation has been a major issue in the field of spatial perception.

The first step is to acknowledge that this distinction exists and is important. With some exceptions (including work on the treadmill effect, described in Case Study 4 below), Firestone and Scholl (in press-a) criticized the field in general for not being sensitive to this important distinction, and indicated several ways to appreciate the distinction. For example, they pointed to occasions on which there is a conflict between perception and judgment (such as with visual illusions). To further expand on the point, they provided numerous examples in which a pattern of results that had been argued to show a perceptual effect could also have arisen from a nonperceptual effect. In another paper, they referred to this use of nonperceptual effects to make implications for purported perceptual effects as the overgeneralization test (Firestone \& Scholl, 2015). These examples of overgeneralization show that researchers cannot make claims that the underlying mechanism is perceptual solely on the basis of finding a particular pattern of results if the same pattern of results can also be found with a nonperceptual manipulation.

The overgeneralization test is valuable for helping illustrate the distinction between perception and judgment, but it is limited in making strong conclusions regarding this distinction. An analogy may be useful to illustrate this point. In visual search tasks, positive search slopes have been taken as evidence for the involvement of serial processes (e.g., Treisman, 1982). Other research has shown, however, that positive slopes in visual search can arise not just from serial search processes, but also from parallel processes coupled with noise (Palmer, Verghese, \& Pavel, 2000). Thus, positive search slopes do not necessitate the involvement of serial processes. Conversely, this result does not prove that serial processes are never involved. Thus, although the overgeneralization test can be used to illustrate how the same pattern can arise from a nonperceptual effect, the test cannot prove, by itself, that a given effect is not perceptual. Other research must be brought to bear on the issue of perception versus judgment. My colleagues and I have made a similar point with respect to perceptual and response-based biases analyzed using signal detection theory (Witt, Taylor, Sugovic, \& Wixted, 2015). Some researchers have claimed, solely on the basis of an effect on the bias measure $c$, that the effect is due to response-based bias and is not perceptual (e.g., Choe, Welch, Gilford, \& Juola, 1975; Grove, Ashton, Kawachi, \& Sakurai, 2012). In contrast, we used simulations of the Müller-Lyer illusion to show that both a perceptual bias and a response-based bias can produce the exact same pattern in the measure $c$. In other words, when the Müller-Lyer illusion is modeled as a perceptual bias in which lines with tails oriented inward appear shorter than lines with tails outward (i.e., the classic interpretation of this bias), 
signal detection theory analyses showed a large effect on $c$ but no effect on $d^{\prime}$. This effect on $c$ coupled with a lack of effect on $d^{\prime}$ does not mean that an effect is due to a response bias. Indeed, we specifically modeled the task as a perceptual bias with no change in response bias, yet $c$ was the measure that showed the effect. Thus, for discriminability experiments, researchers cannot simply look at a pattern of results for $c$ and draw the conclusion that the underlying mechanism is response-based. Other research must be brought to bear to address the underlying mechanism.

So what strategies are available to empirically discriminate between perception and judgments? Given the rich history in the field of depth perception with respect to distinguishing perception from judgments, several strategies exist within the literature. For reasons unknown, Firestone and Scholl (in press-a) neglected this aspect of the literature and the strategies promoted within this field for decades, as well as in a recent review of these strategies (Philbeck \& Witt, 2015). It would be a mistake for other scientists working on this problem to ignore these elegant contributions. One strategy common within the distance perception literature is the use of convergence across a wide range of perceptual measures. The idea is that an effect common to all measures is likely to be due to a single underlying process - perception, in this case - as opposed to the individual processes involved in generating and calibrating each type of response (Foley, 1977; Gogel, 1990; Philbeck \& Loomis, 1997). As I discussed above, in my lab we have used several types of perceptual measures, and all have revealed the same pattern of the paddle effect. Future research, however, could offer a more direct comparison between the various kinds of responses as a way to determine the size of the purported perceptual effect. Any unique, additional effects would be considered to be due to the judgment-related processes involved in each of the individual types of responses. Converging evidence does not, in and of itself, prove that a given effect is perceptual. However, it helps us build a case for a perceptual effect, given that a lack of convergence would raise serious doubts about the perceptual nature of an effect. Perhaps converging evidence is best characterized as a necessary but not sufficient condition to claim that a particular effect is perceptual.

Another technique common in the literature on spatial perception is to use indirect measures (see, e.g., Gogel, 1990). Indirect measures are thought to be purer measures of perception, and less contaminated by judgment-based processes, because it is not obvious to the observer how to adjust these responses. Indirect measures have not yet been applied to the paddle effect, and this could prove to be a fruitful avenue for future research. Again, it will be important to achieve convergence, rather than effects within a single type of measure, even if that measure is indirect. At this point, it is unclear how many strategies must be employed before researchers can claim a perceptual, rather than a judgment-based, effect.
Firestone and Scholl (in press-a) offered three of their own strategies. One was to examine convergence across a range of different instructions. Participants can be instructed to report on objective speed, apparent speed, or "felt" speed (by asking how fast they feel the ball to be moving). Some researchers have suggested that instructions to report on apparent features such as speed or distance will minimize the amount to which participants correct their judgments (Carson, 1977). Others have found that the action-specific effect of heavy ball throwing on estimated distance (cf. Witt, Proffitt, \& Epstein, 2004) only replicated under the "felt" instructions (Woods, Philbeck, \& Danoff, 2009), which was interpreted as evidence that this effect was judgment-based rather than perceptual. The paddle effect has not yet been investigated under differing instructions, although studies are currently under way to do so.

The second suggestion was to consider factors that might affect judgments and rule these out. If factors that should affect judgments are eliminated and this also eliminates the critical effect, that is evidence for a judgment-based rather than a perceptual effect. For example, the effect of dartthrowing performance on estimated size could occur because performance influences perceived size or because participants alter their judgments after missing the target to account for their poor performance. When participants were given an external reason for the poor performance (faulty darts), there was no need to justify performance, and in this case it was found that performance did not relate to estimate size (Wesp \& Gasper, 2012). ${ }^{1}$ Although I admire the logic of this experiment, I hesitate to accept its results, because the dart-throwing paradigm does not appear to be particularly robust. Many of the reported "significant" findings have been only marginally significant $(p \mathrm{~s}=.06, .001$ and .02 , and .05 in Canal-Bruland, Pijpers, \& Oudejans, 2010; Wesp, Cichello, Gracia, \& Davis, 2004; and Wesp \& Gasper, 2012, respectively). Given the lack of strong evidence for an effect in dart-throwing paradigms, the reported null results on which many of the strong claims hinge are particularly difficult to interpret.

Nevertheless, the logic offered by Wesp and Gasper (2012) and urged by Firestone and Scholl (in press-a) can be applied to the paddle effect. Participants were split into two groups, and each group was told a cover story that the task of blocking the ball would be either hard, because the ball would bounce at

\footnotetext{
${ }^{1}$ Wesp and Gasper (2012) also suggested that the differences in distance estimates across participants who threw a heavy versus a light ball could have been due to a similar pattern of participants accounting for poor throwing performance by estimating that the distance was farther. But this suggestion ignores an experiment within the same paper, in which all participants threw the heavy ball, but only those who intended to throw again estimated the distance as being farther, as compared to those who threw the heavy ball, estimated the distance, and then blindwalked to the target (Witt et al., 2004). In that experiment, the participants in both groups had similar throwing success because both threw the heavy ball, yet differences in the estimated distances still emerged as a function of the action they anticipated performing next (throwing vs. walking).
} 
random, or easy, because they had full control over the paddle (Witt, Tenhundfeld, \& Bielak, in press). In actuality, the task was the same for both groups. This cover story had no effect on the magnitude of the paddle effect for either group. Given that the cover story did not reduce the paddle effect, this is evidence against a judgment-based explanation of the paddle effect. Furthermore, the results cannot be dismissed by arguing that the cover story was ineffective, because it impacted another effect that is considered to be judgment-based. In the Pong paradigm, the primary effect of interest is that of paddle size on estimated speed. When the paddle is big, participants can anticipate that they will be more likely to be successful at blocking the ball than when the paddle is small. This anticipated success, and perhaps also the added concentration necessary to achieve success with the small relative to the big paddle, is what we think drives the differences in perception of ball speed. A secondary effect is that of trial outcome, which refers to whether the ball was missed or successfully caught on each trial. The trial outcome effect refers to the influence of trial outcome on estimated speed, such that balls that are successfully caught are estimated as moving slower than balls that are missed. The trial outcome effect is considered to be a judgment-based effect, given that outcome is unknown until the end of the trial, and therefore is unlikely to be able to influence visual processing while the ball is moving. Whereas the paddle effect is considered to reflect anticipation and is argued to be perceptual, the trial outcome effect reflects recent past experience and is considered to be judgment-based. We found evidence of a divergence between the impact of the cover story on these two effects. For participants who were better blockers, the "hard" cover story successfully eliminated the trial outcome effect, whereas the trial outcome effect was still significant for those told the "easy" cover story. The overall pattern of results that the cover story eliminated the judgment-based effect of trial outcome but had no impact on the paddle effect is evidence against a judgmentbased explanation for the latter effect.

A third suggestion by Firestone and Scholl (in press-a) was to use performance measures. They suggested reaction time in a visual search task as a possible example. It is difficult to see how a visual search paradigm could be applied to the paddle effect, or to any other action-specific effect, for that matter, but other kinds of performance measures are possible. In a variation of the Pong paradigm, called the fishing task, a fish moved horizontally across the screen, and a net was placed in the bottom right corner (see Fig. 3). Participants pressed the trigger on the joystick to shoot the net, at which point the net moved up the screen at a constant speed. To successfully catch the fish, participants had to release the net at the exact right moment so that the net intersected the fish as the fish traveled across the screen. Again, the ease of catching the fish was manipulated by varying the size of the net, and participants caught the fish more successfully when the net was big than

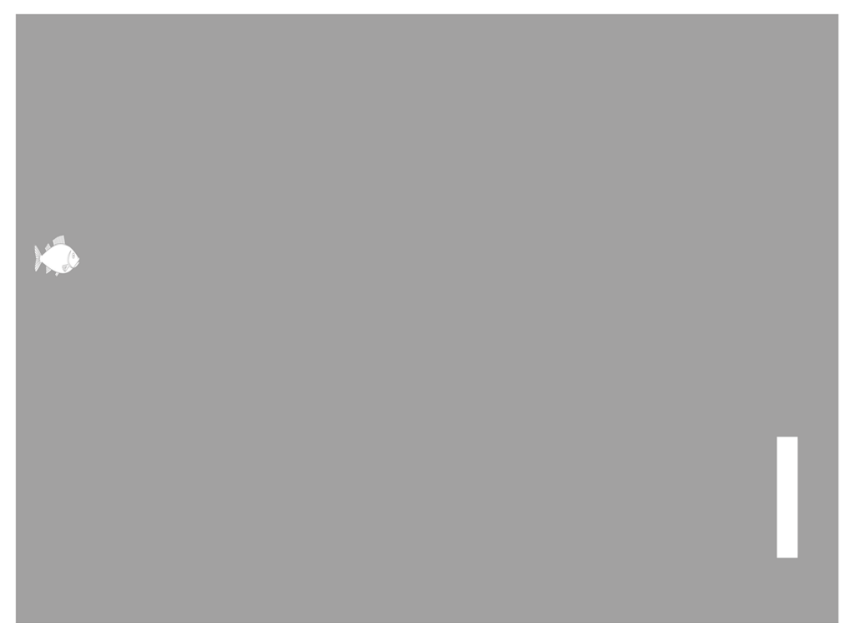

Fig. 3 Screen shot of the fishing paradigm (Witt \& Sugovic, 2013a). The medium net is shown. The net stays at the bottom of the screen until the participant presses the trigger on the joystick, at which point the net moves up at a constant speed. If the timing is correct, the fish will intersect the net for a successful catch. From Fig. 1 of "Catching Ease Influences Perceived Speed: Evidence for Action-Specific Effects From Action-Based Measures," by J. K. Witt and M. Sugovic, 2013, Psychonomic Bulletin \& Review, 20, p. 1366. Copyright 2013 by the Psychonomic Society. Reprinted with permission

when it was small. After each attempt participants estimated the speed of the fish, and they estimated that the fish was moving faster when the net was small than when it was big (Witt \& Sugovic, 2013a).

The new advancement from the fish paradigm is that it affords a performance measure of perceived speed: If participants truly see the fish as moving faster when the net is small, they should shoot the net earlier than when the net is big. We examined the timing of the responses, and the results corroborated the paddle effect; participants shot the small net earlier than the big net, indicating that the fish appeared to be moving faster when the net was small. Despite the advantages of using action-based measures, their use also raises issues regarding whether effects are due to perceptual differences or differences in the actions themselves. As a simple example, if the nets were aligned at the bottom, rather than in the middle, this would lead to different release times independently of any differences in perception. In our studies, the nets were aligned in the middle, thus ruling this out as a potential concern. However, another concern may be that participants aimed for the middle of the small net but for the top of the big net. This strategy would have produced the same pattern of results that we obtained, without needing to assert any differences in perception. Although previous research has shown that people tend to be good at aiming for the middle of a target to best increase performance (Trommershäuser, Maloney, \& Landy, 2008), it was still important to determine that a strategy could not account for the results in the fish study as well. Follow-up analyses revealed that participants aimed for the center of the net with all net sizes, thereby ruling out the possibility that the 
differences in net shooting times were due to different strategies for how to use the net. Having ruled out nonperceptual explanations for the differences in net release times, the results support the claim that participants perceived the fish as moving faster when the net was small. With net shooting times as a measure of perceived fish speed, no explicit judgment was required. Yet the effect of performance on perceived speed was still apparent.

Together, the present results demonstrate that the paddle effect persists even when using multiple types of measures, thus demonstrating convergence, and also when using the performance measure of net release time. The results also rule out an obvious judgment-based explanation by showing that the effects of paddle size persist even after accounting for potential post-hoc judgments based on trial outcome. Although more studies could certainly be conducted, the present data already do much to rule out a judgment-based effect.

\section{Pitfall \#3: Demand and response bias}

The most frequent challenge to action-specific effects has been the claim that they are due to demand characteristics or response bias (Durgin et al., 2009; Durgin, Klein, Spiegel, Strawser, \& Williams, 2012; Shaffer, McManama, Swank, \& Durgin, 2013). According to this claim, participants do not literally see the ball as moving faster when the paddle is small, but rather see the ball's speed similarly across paddle sizes. The reason for the differences in their perceptual judgments is that participants infer that the purpose of the experiment is that the ball should look faster when it is harder to block, and respond accordingly. The Pong paradigm might be especially susceptible to this concern, given that the design is withinsubjects, so participants are aware of all of the conditions (Philbeck \& Witt, 2015).

The evidence offered as being in favor of task demands has generally relied on the use of cover stories or postexperiment surveys. With respect to asking participants whether they could discern the purpose of the study in an open-ended question, generally only $25 \%$ guess correctly (e.g., Durgin et al., 2012; Shaffer et al., 2013). This number is much lower than would be expected on the basis of how proponents of the response bias account describe these effects, in which the study's purposes would be clearly obvious and thus would naturally impact all responses. With respect to the paddle effect, we recently interviewed participants upon completion of the experiment (Witt \& Tenhundfeld, Manuscript in preparation). Consistent with the past literature, we also found that $25 \%$ guessed correctly when asked an open-ended question about the study's purpose. Importantly, those who guessed correctly did not show larger paddle effects than did those who did not guess correctly, and thus could not have driven this effect (see Fig. 4). Such low numbers of discernment raise questions about the need for cover stories in the first place, because such stories would be
12

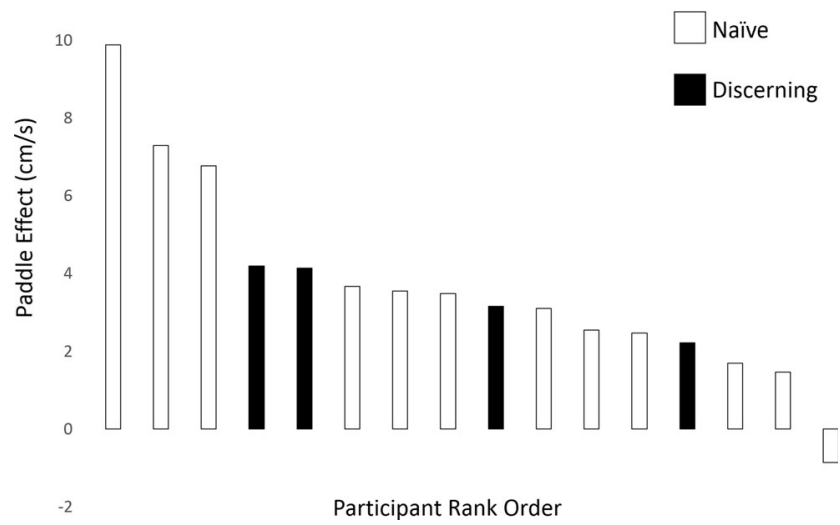

Fig. 4 Paddle effect for each participant from a study in which they were asked to indicate what they thought was the purpose of the study (Tenhundfeld \& Witt, Manuscript under review). Those who mentioned the size of the paddle were classified as discerning, and those who did not mention paddle size were classified as naïve

necessary only for $25 \%$ of participants. Furthermore, cover stories carry with them their own risks of creating, rather than eliminating, response biases. For example, the participants in one experiment were explicitly told, "as far as we know, wearing a backpack does not affect your visual system, so please simply estimate the slope of the hill" (Durgin et al., 2012, p. 1585). It is not difficult to see how instructions such as these, despite the intention to eliminate response bias, could actually create their own response bias to respond that the hill is shallower even if it appears steeper. Finding that participants given these instructions report that hills are less steep is therefore not evidence that hills genuinely did not look steeper.

Given the issues with cover stories creating their own biases and the low numbers of participants who can correctly discern or guess the study's purpose, we have sought alternative methods to address the issue of demand characteristics. One method has been to show that differences in estimated speed across paddle sizes that might create a demand characteristic do not always lead to effects on perceived speed. These studies were reviewed in light of the disconfirmatory predictions.

Another strategy has been to consider the effect of trial outcome, rather than paddle size. As was stated earlier, an effect based on trial outcome refers to an influence on estimated speed that is based on whether the ball was successfully caught or missed on each trial. A response bias account would claim that participants would be more likely to rate missed balls as fast and caught balls as slow (cf. Wesp \& Gasper, 2012). These theorized changes in responses would produce the reported paddle effect because the ball is missed more frequently with the small than with the big paddle. However, when we analyzed trial outcomes, we found that the trial outcome could not explain our results. The differences in speed ratings for missed versus caught balls were unreliable: Some 
studies showed significant effects of trial outcome, but most did not (for an extended discussion, see Witt, Tenhundfeld, \& Bielak, in press). Moreover, trial outcome never fully accounted for the effect of paddle size, which continued to be significant even when trial outcome was included as a predictor. This pattern of results suggests some role for response bias related to the trial outcome, but that this role is not robust and cannot explain the main effect that is argued to be perceptual - namely, the paddle effect.

Another strategy has been to measure susceptibility to response bias directly. The response bias explanation requires that participants willingly alter their responses according to demand characteristics. Thus, if the paddle effect were to only emerge for participants willing to alter their responses, but not for participants who did not conform to the demand characteristics, this would be strong evidence in favor of a response bias explanation. Participants were given instructions to specifically bias them to respond that the balls were fast (or slow): Participants in the group that was instructed to respond "fast" responded faster than did those who were instructed to respond "slow," showing overall compliance with these instructions. To determine which participants were more compliant than others, we conducted a median split on each group based on their mean speed responses. The participants who were given instructions to respond "fast" were classified as more compliant if they responded that the ball moved faster than did the other participants, and were classified as less compliant if they responded that the ball moved slower than did the other participants. Once the participants were grouped on the basis of compliance, we compared the paddle effects in both groups; paddle size influenced the judged ball speeds for both groups equally (Witt \& Sugovic, 2013b). This means that even participants who were less willing to alter their responses to conform to the instructions were still influenced by the difficulty associated with blocking the ball (as determined by paddle size). Given that a response bias account would have predicted an effect only in the compliant participants, the results are evidence against a response bias explanation and are consistent with a perceptual account that task difficulty influenced the perceived ball speed. The paddle effect is quite robust and is present in most participants (including 33 of the 35 participants in that experiment), and thus is not an effect that was driven by a subset of participants who were particularly compliant. Several other methods were used to classify the participants as more and less compliant, and each produced similar paddle effect sizes (see the appendix in Witt \& Sugovic, 2013b).

A final strategy has been to give explicit feedback on speed judgments (King, Tenhundfeld, \& Witt, 2015, 2016), which is a strategy previously employed in crossmodal research (e.g., Rosenthal, Shimojo, \& Shams, 2009). Participants classified each speed as being more like the slow or more like the fast anchor speeds. The ball moved at six speeds, so the three slowest speeds should be classified as "slow," and the three fastest speeds should be classified as "fast." In the first experiment to use feedback, the study was divided into three phases: baseline, feedback, and feedback recovery. During the feedback phase, participants heard a buzzer and saw the word "incorrect" each time they made the wrong response. No feedback was given for a correct response or during the other phases. Relative to baseline, the feedback condition did not lead to a significantly reduced paddle effect; paddle size influenced estimated speed even when feedback was given. A follow-up experiment delivered feedback for incorrect responses across the entire experimental session, and once again the effect of paddle size persisted. With feedback, it is clear that the task is to be as accurate as possible in one's speed judgments, which would diminish any effects of demand characteristics (including any related to paddle size) on estimated speed. Given that perceptual speed judgments continued to be influenced by the difficulty associated with blocking the ball with each type of paddle, these results provide evidence against a response bias account and in favor of a perceptual account.

\section{Pitfall \#4: Low-level differences}

The visual information specifying the speed of the ball was constant across paddle size conditions, and thus cannot account for differences in apparent speed. However, it is possible that visual information related to paddle size, which obviously differed as paddle size was manipulated, biased the perceived speed of the ball independently of action. In the original Pong article, in the final experiment we placed the paddle atop a long white rectangle to minimize the luminance differences across paddle size conditions (Witt \& Sugovic, 2010). The paddle effect emerged even when luminance differences were completely eliminated. Other studies have maintained the visual differences between paddle size conditions, and instead minimized differences in the effectiveness of the paddle at blocking the ball. If low-level differences were to account for these effects, the effect should be present when visual differences are maintained even if action-related factors are eliminated. As was discussed in the studies on disconfirmatory findings, in many instances visual differences were present and performance differences were minimized. In these cases, differences in perceived speed due to paddle size were also eliminated. This evidence rules out the explanation of low-level visual differences.

Couched within this pitfall was a call for amazing demonstrations, because the case study described for this pitfall was one of the few purported top-down effects that was also accompanied by an amazing demonstration, and they argued that this particular effect was due to low-level differences (Firestone \& Scholl, in press-a). After this introduction, the amazing demonstrations discussed were not related to lowlevel differences, nor were they mentioned in lessons for 
future research, but instead were related to the other pitfalls, such as task demands and postperceptual judgments. So perhaps it would make more sense to discuss demonstrations under these pitfalls than under low-level differences. Nevertheless, in being consistent with their original proposal, they will be discussed here.

Amazing demonstrations are certainly fun and can be compelling. But are demonstrations necessary to prove that an effect is perceptual? Firestone and Scholl (in press-a) conceded that they are not necessary. However, the issues of awareness, noticeability, and amazing demonstrations have been raised a number of times (Firestone, 2013; Gray, 2016; Loomis, 2016; but see the responses by Witt, 2015; Witt, Linkenauger, \& Wickens, 2016). In some areas of vision science, such as change blindness or motion-induced blindness, demonstrations are readily available and often accompany the research by being available on a webpage. However, in research on spatial perception in real-world environments, demonstrations are hardly ever offered. For example, a noteworthy bias in distance perception is compression of egocentric distances (e.g., Loomis, da Silva, Fujita, \& Fukusima, 1992). I do not know of any spatial-perception researchers who would doubt that this is a perceptual bias, but no public demonstrations of the effect are available. Similarly, distances look shorter when they are presented in a larger rather than a smaller space (Witt, Stefanucci, Riener, \& Proffitt, 2007). Again, this work is unlikely to be challenged as being perceptual, despite the lack of an accompanying demonstration.

Firestone and Scholl (in press-a) explicitly stated that amazing demonstrations are not necessary for an effect to be considered perceptual, yet they also seem to argue that without an amazing demonstration, action-specific effects should not be considered perceptual (see also Firestone, 2013). Therefore, they have not been clear as to what is necessary and sufficient, and these issues are not simple.

Action-specific effects cannot be uploaded to a webpage like other perceptual phenomenon, because action-specific effects require interaction with the target object (or at least the intent to interact). In addition, the definition of an amazing demonstration has not been made explicit. For some, the argument is that observers should notice a change in what they see (e.g., the hill should appear to grow in steepness when a backpack is put on) and a lack of noticing such a change is evidence against a perceptual explanation (Firestone, 2013). I had previously argued against this type of noticeability being necessary, when I showed that observers were not aware of a change of apparent size when a circle was first surrounded by small inducer circles that switched to be large inducer circles (Witt, 2015). In other words, the two conditions of the Ebbinghaus illusion did not lead to awareness of changes in perceived size, even though the two conditions of the Ebbinghaus illusion do typically lead to differences in perceived size. An important characteristic of spatial perception that has been neglected within calls for amazing demonstrations
(Firestone, 2013; Firestone \& Scholl, in press-a) is the issue of perceptual stability. The visual system prioritizes stability so that conditions that would ordinarily lead to differences in perception (such as the Ebbinghaus illusion) do not do so when there are cues that the world is stable (i.e., has not changed). Proposing demonstrations such as putting on a backpack while looking at a hill or imagining reaching with a tool are unlikely to cause a noticeable change in the perceived hill slant or target distance, because these effects are unlikely to be strong enough to overcome the cue to stability. Additionally, when observers have explicitly noticed this kind of change (as was the case in Case Study 3 offered below; Linkenauger, Ramenzoni, \& Proffitt, 2010), this observation was not taken as the kind of compelling evidence Firestone and Scholl (in press-a) suggested it should be.

A second type of demonstration is that observers notice that how something looks is different from how the object looked previously. In this case, there can be the experience of a difference between one's perception of the object and one's memory of the object. In one study, this very discrepancy was documented for elite track athletes. A track has the advantage that it is of a fixed length, so runners know that the track's length has not changed. Such knowledge is not as readily accessible in cases such as hill slant or unmarked distances, and thus cannot be used to appreciate any contrast. Of the 34 athletes in the study, $80 \%$ reported seeing the straight sections of the track as appearing longer, especially when they were running a longer race or were tired (Witt, 2015). Indeed, I decided to run this particular study after having similar experiences running on the track myself. If willing, a reader could run nine 400-m sprints and experience for herself whether the track seemed longer on the eighth or ninth sprint than on the first or second. These were conditions in which I was able to experience an action-specific effect.

A third type of demonstration is that observers see two objects at the same time and notice that one object appears different from the other, despite knowing that the two objects are the same (or, conversely, see that two objects appear the same, despite knowing that they are different). Visual matching tasks, which have been used in a variety of actionspecific effects (see some examples below), address this to some extent. For example, if the comparison distance is set to be different from the target distance but is judged to be the same, this shows that the two distances are experienced as different lengths. However, to my knowledge, this has never been tested in the context of explicit feedback about the actual objects. This may be one way to help address this concern in the future. Participants could be shown two objects - or in the case of the paddle effect, two speeds - and explicitly told that the speeds are the same, and then asked whether they appear different. Such data might prove compelling as a demonstration and are certainly worthy of future investigation, since they could help build a case for a perceptual account of these effects. 


\section{Pitfall \#5: Attentional effects}

Attention could explain the effect of paddle size on apparent speed, because it is known that where a person looks affects perceived speed. The Aubert-Fleischl illusion shows that smooth pursuit of a moving object leads to the perception of the object as moving slower than when a nearby stationary location is fixated instead (Aubert, 1886; Fleischl, 1882). Applying this illusion to the Pong paradigm, perhaps participants are more likely to engage in smooth pursuit of a ball when the paddle is big, and that is why the ball appears slower than when the paddle is small.

The theoretical implications of finding that this particular pitfall can explain an effect are less clear than with the other pitfalls. On one hand, the pitfall is critical to Firestone and Scholl's (in press-a) claim that perception is modular. But the pitfall is not as relevant for the main claim of the actionspecific account that perception differs as a function of action. The reason that this particular outcome can be consistent with two seemingly opposing claims is that the claims differ with respect to whether they concern the process or the experience. Firestone and Scholl (in press-a) were mainly concerned with the processes related to perception; their main claim was that these processes are modular and impenetrable to top-down influences. In contrast, my claims have primarily been concerned with perceptual experience. I claim that the perceptual experience of spatial layout is influenced by a person's ability to act. Whether or not an action's impact on that experience is due to direct influences on perceptual processes or to indirect influences via attention is a secondary issue. To be sure, this question is critical for understanding how action exerts its influence (Gray, Navia, \& Allsop, 2014; Philbeck \& Witt, 2015), but it is irrelevant for understanding whether action influences perception.

In the case of the paddle effect, however, this distinction is irrelevant, because attention does not drive the paddle effect. Attention was equated across paddle size conditions by the inclusion of a secondary task that forced participants to look directly at the fish throughout the experiment. If differences in attention accounted for the effect of paddle size on perceived speed, then equating attention across paddle size conditions should eliminate the effect altogether. We found that paddle size continued to influence perceived speed, even when attention was equated (Witt, Sugovic, \& Dodd, 2016). This finding rules out an attentional explanation for this action-specific effect.

\section{Pitfall \#6: Perception versus memory}

In most experiments, participants judged the speed of the ball after each blocking attempt, so the ball was no longer visibly moving. This created the possibility that blocking ability affected immediate memory for, rather than the perception of, speed. To address this possibility, we ran several experiments in which participants made their judgments while the ball was still visibly moving (Witt \& Sugovic, 2012). In one experiment, participants performed the speed-bisection task. In another, participants rated the ball on a scale of 1 to 7 . In both cases, the participants said their responses aloud, and the response was recorded by an experimenter. Paddle size affected the estimated speed even when judgments were made while the ball was visibly moving.

In addition, the action-based measure in the fishing task of shooting the net also demonstrates an effect of perception, rather than or in addition to memory (Witt \& Sugovic, 2013a; Witt, Sugovic, \& Dodd, 2016). The fish was visibly moving when participants shot the net, and net size still had a significant effect on the action-based measure of net shot timing. Thus, as to whether action can influence perception, the evidence makes a convincing case that it can.

\section{Summary}

Moving objects appear faster when they are more difficult to block than when they are easier to block. Evidence exists to evaluate each of the six pitfalls listed above. In each case the effect passes the test, so to speak. Because the paddle effect survives all six pitfalls, the conclusion is that it is a genuine top-down effect of action on perception. Finding that one action-specific effect is genuinely perceptual is sufficient to discredit the claim that no top-down effects on perception exist.

\section{Case Study 2: Ability to reach a target affects perceived distance}

A person's ability to reach to an object influences perceptual judgments of the distance to the object. Specifically, targets appear closer when they can be reached than when they are beyond reach. This would appear to be trivially true, given that targets that are within reach are closer than targets beyond reach. To keep the physical distance to the target constant across reaching conditions, one technique is to give perceivers a reach-extending tool (Bloesch, Davoli, Roth, Brockmole, \& Abrams, 2012; Costello et al., 2015; Davoli, Brockmole, \& Witt, 2012; Osiurak, Morgado, \& Palluel-Germain, 2012; Witt, Proffitt, \& Epstein, 2005). In this way, the visual information specifying the distance to the target is the same, even as the reachability of the target changes.

In these reaching paradigms, participants typically estimate the distance to the target by performing a visual matching task (see Fig. 5). Two comparison circles are presented on either side of the target, and participants can use a keyboard to manipulate the distance between the two comparison circles. Participants indicate when the distance between the comparison circles is the same as the distance to the target, and then 


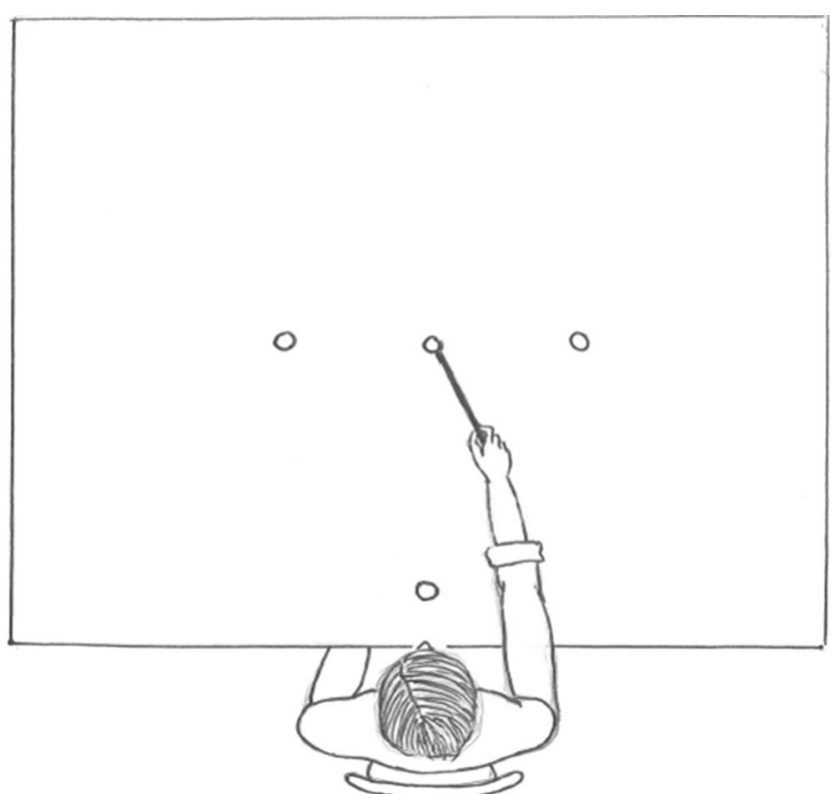

Fig. 5 Overview of the visual matching task used in the tool studies by Witt et al. (2005). Three circles are projected onto a table. The center circle is the target for reaching, and the outside circles are the comparison circles. A paper circle is placed directly in front of the observer. Participants use a keyboard to move the comparison circles closer together or farther apart. Their task is to set the distance between the comparison circles to be the same as the distance to the target, and then to reach toward the target with or without the tool. Drawing by Nicole Versace

reach toward the target. If the target is too far away to be reached, participants reach as far as they can and point to the target. The targets are presented just beyond arm's reach, but can be reached with a reach-extending tool such as a conductor's baton. Typical results are that the targets are judged to be closer when participants reach toward them with a tool than when they reach without the tool.

\section{Pitfall \#1: Uniquely disconfirmatory predictions}

Many variations of the tool studies have been conducted, including several in which uniquely disconfirmatory predictions have been made. One variation has been to dissociate the perceiver's ability to act at the moment the perceptual judgment is made from the ability to act when the action is performed. This has been done, for example, by having the tool resting on the table while the participant positioned the comparison circles (Witt \& Proffitt, 2008). After the two distances were matched, the participant picked up the tool and reached toward the target, before placing the tool back on the table and starting the next trial. Because participants performed the same sequence repeatedly, they intended to reach toward the target with the tool even though they were not holding the tool while estimating the distance. The experiment was originally designed to test the idea that anticipated action is the critical aspect relevant for perception. Consistent with this hypothesis, perceivers judged the targets to be closer when they anticipated reaching toward them with a tool, even if participants were not physically wielding the tool at the time of the judgment.

Notably, participants also judged the targets as being closer when they imagined holding a tool (Witt \& Proffitt, 2008; see also Davoli et al., 2012). In this case, the tool rested on the table, but participants never grasped it. Instead, they reached as far as they could toward the target and imagined that they held the tool and touched the target with it. For some researchers, these findings may seem to support a judgmentbased explanation rather than a perceptual one, given that participants were consciously imagining an action (reaching while imagining holding a tool) rather than performing an action (such as reaching with the tool). However, we have argued that these studies are consistent with a perceptual explanation because prior research has shown that imagining an action engages neural processes similar to those involved in actually performing an action (Grèzes \& Decety, 2001), and it was theorized that these processes are involved in predicting the outcomes of the actions as they relate to perceived distance (Witt \& Proffitt, 2008). The critical experiment with a disconfirmatory prediction was conducted next. Instead of imagining a physically possible action, which would engage motor-related processes (Grèzes \& Decety, 2001), participants were instructed to imagine the physically impossible action that their arms could extend all the way to each target (like the characters Gumby or Inspector Gadget). In this case, participants were still instructed to imagine that the target could be reached, but now the mechanism no longer engaged motorrelated processes. In this experiment, those who imagined their arm extending did not judge the targets to be closer than did the group that reached without the tool. This provides a uniquely disconfirmatory finding, because according to response bias accounts, the targets should have been judged as being closer because participants were told to imagine that they could reach all the targets. Yet this still did not influence the perceptual judgments. A potential alternative explanation is that the participants in the no-tool-and-imagine conditions reached to their full extent on each trial, and thus had to exert more effort than did the participants in the tool condition. However, we think it is unlikely that the small differences in effort across such a short time interval would have been sufficient to produce differences in perceived distance. Although the exact amount has yet to be determined, there is an expectation that the magnitude of a difference in required effort must reach some critical threshold before any difference in perception will be apparent.

In another study, participants reached with a long or a short tool (Osiurak et al., 2012). The short tool did not impact the perceiver's ability to reach, and therefore was not theorized to impact perception. As expected, the targets appeared closer for participants who reached with the long tool than for participants who reached with the short tool. The short tool could 
have impacted judgments, had these effects been driven by response biases, but it did not, thereby providing another disconfirmatory finding.

Another method to alter reachability has been to use a virtual reality in which the person's arm is rendered within the environment (Linkenauger, Bülthoff, \& Mohler, 2015). The arm can be rendered to be longer or shorter, thereby altering the reachability of objects without changing the visual information that specifies the distance to the object. When the arm is rendered longer, and thus can reach farther, objects appear closer than when the arm is rendered shorter. Critically, the effect of arm length only alters the apparent distance to targets when the arm is functional and participants have experience moving the arm. Again, the null finding when participants cannot control the arm provides a uniquely disconfirmatory finding. This finding also rules out potential low-level visual differences between the two arm conditions, because the visual information was similar across experiments, but the size of the arm only impacted distance judgments when it was functional.

\section{Pitfall \#2: Perception versus judgment}

An important technique for examining effects based on the underlying perception versus judgments is to use indirect measures (Gogel, 1990; Loomis \& Philbeck, 2008). Indirect measures allow for the measurement of one feature by asking questions about another feature. For example, in the tool studies, perceived distance was assessed by asking participants to make judgments about an object's shape (Witt, 2011). The target was a circle presented just beyond arm's reach. Two other circles were presented well within reach (and therefore were theorized not to be influenced by wielding a tool, because they were already reachable). The three circles comprised a triangle (see Fig. 6). In one experiment, participants estimated the shape of the triangle by adjusting the shape of a comparison triangle presented on a nearby computer monitor. ${ }^{2}$ In another experiment, participants adjusted the two base circles so that the triangle was equilateral. In both cases, participants who intended to reach with a tool judged the triangle to

\footnotetext{
${ }^{2}$ As is shown in Fig. 6, the head was not restrained, so visual angle was not tightly controlled. Although participants made their perceptual judgments prior to reaching, it is possible that the participants in one condition adopted a different posture than did the participants in the other condition, and that these differences in visual angle produced the differences in perceived shape. This seems unlikely, especially in the experiment in which participants had to match the triangle on the nearby monitor, given that participants had to look back and forth repeatedly; thus, there was likely to be variability in viewing angle anyway, making it unlikely that there would be consistent, systematic differences. Nevertheless, this possibility could be tested directly. However, in other experiments that have used similar visual matching tasks but that involved direct estimates of distance (rather than shape), viewing angle has been controlled, and this has not eliminated subsequent tool effects on estimated distance (Bloesch et al., 2012; Costello et al., 2015).
}

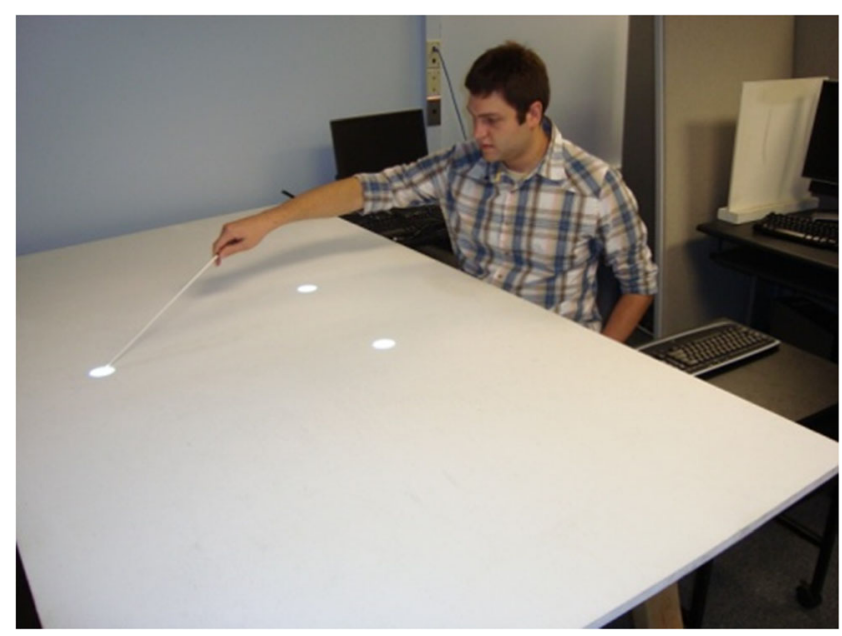

Fig. 6 Experimental setup for studies using perceived triangle shape as an indirect measure of perceived distance. Participants estimate the shape of the triangle and then reach to the far circle

be squatter or shorter than did participants who intended to reach without the tool. The implication is that the reason the triangle appeared squatter is that the target appeared to be closer. In a follow-up experiment, the target circle was presented beyond arm's reach, and three comparison circles were presented within arm's reach. Participants had to position the two closer circles so that they comprised a line that was parallel to the line formed by the two far circles (one of which was the target). If the target appeared closer when reaching with a tool, that line should appear more horizontal. Indeed, participants who intended to reach with the tool positioned the near line to be more horizontal than did the participants who reached without the tool. Again, this indirect measure of perceived parallelism suggests that the target appeared to be closer. The use of indirect measures has been explicitly suggested as a way to determine whether action influences perception or judgment (Loomis \& Philbeck, 2008). As I discussed earlier, convergence between multiple measures is critical for determining that an effect is perceptual. In the case of the tool effect, convergence has been documented across verbal estimates, direct visual matching tasks, and several indirect visual matching tasks. Thus, the evidence suggests a perceptual effect.

\section{Pitfall \#3: Demand and response bias}

Consider how response bias could account for the effect of using a tool on the judged distance to an object. Participants are asked to estimate distances to objects, then are given a tool and asked to estimate again (or the order is reversed). Participants often suspect that their responses should not be the same across the various conditions (Poulton, 1979). The use of the visual matching task helps subvert this concern, because it is quite difficult to remember how the circles were positioned during previous trials. In addition, several 
variations of the tool studies could easily have led to similar response biases, but did not lead to effects on apparent distance. For example, when participants were explicitly instructed to imagine that their arm could stretch and reach to all targets (Witt \& Proffitt, 2008), this was a good setup for a response bias, because the participants were specifically told to visualize the targets as being within reach. As another example, when participants were given a short tool to use to reach, this could have also led to a response bias to estimate targets as being closer (Osiurak et al., 2012). In the experiments comparing long and short tools, response bias was further addressed, because participants were given a cover story explaining why they were being asked to hold the tools; specifically, they were told that the tool was meant to standardize hand and arm position across participants. Given the claim that such cover stories should eliminate effects due to response bias, the finding that targets were estimated as being closer when reaching with the long tool, but not with the short tool or in a no-tool condition, is evidence against a response bias explanation for this particular effect. Additionally, in one experiment the participants were asked to estimate the distance to targets while holding or not holding the tool. They were never asked to reach with the tool, but there was an obvious difference between the two conditions in which they did or did not hold the tool (Witt et al., 2005). Yet this obvious difference did not suffice to produce differences in their judgments of perceived distance. Only when participants used the tool to reach did they estimate the targets as being closer. This also provides yet another uniquely disconfirmatory finding. To date, several studies have assessed perceived distance under conditions that should have led to response biases, but did not, suggesting that when effects have been found, they have not been due to response bias.

\section{Pitfall \#4: Low-level differences}

The tool was used to specifically change reaching potential without changing the visual information. Thus, differences in the visual information could not have produced these effects, because there were no differences. A potential argument is that the tool was visible in some conditions but not others. However, neither visibility nor even the wielding the tool was sufficient or necessary to produce a difference in perceptual reports of distance.

\section{Pitfall \#5: Attentional effects}

Attention has never been explicitly examined within this paradigm, presumably because it is so unlikely that participants would look anywhere other than the target itself. In addition, if anticipated use of the tool does produce systematic changes in attentional patterns, these changes would not be incidental to the task, nor would they be incidental to perception itself.
From the perspective of understanding whether or not action affects perceptual processes directly, research on attention in the tool task needs to be conducted. But from the perspective of whether action can influence perceptual experience, the role of attention is relevant only for understanding whether the effect is direct or indirect.

An important issue to appreciate is that for attention to be a potential culprit in the tool effect, it must be the case that attention can alter perceived distance. Some research has shown that the fixation location can impact the perceived distance to targets within this range of distances, but this research has been conducted in severely reduced-cue environments (Gogel \& Tietz, 1977). One should be cautious to generalize findings from reduced-cue environments to the full-cue environments used to assess action-specific effects, because many perceptual phenomenon found in reduced-cue environments are not found, or their effects are substantially diminished, in full-cue environments (see, e.g., Ooi, Wu, \& He, 2006). Without empirical evidence to support a role for attention, this pitfall is not a viable alternative explanation for the tool effect.

\section{Pitfall \#6: Perception versus memory}

Participants always made their judgments of distance with the target fully in view. In the case of the visual matching task, both the target and the comparison circles were present, and participants looked back and forth between the two extents. Similarly, when they were asked to make the triangle equilateral, participants would have looked at the target throughout the task. Thus, effects within memory cannot account for these particular action-specific effects.

\section{Summary}

When a person attempts to reach to an object, the object appears closer when it can be reached than when it cannot be reached. Experiments have examined this effect by including a reach-extending tool, so that the targets are in the same position and only reachability is manipulated. In evaluating the evidence for this effect within the framework of the six potential pitfalls, the conclusion is that the effect is a genuine top-down effect of action potential on distance perception.

\section{Case Study 3: Ability to grasp an object affects perceived size}

Just as reachability affects the perceived distance to objects, graspability affects the perception of their size. Altering graspability is not as straightforward as giving perceivers a tool to extend their reach. Instead, various manipulations have been used to alter apparent hand size instead. One such manipulation is to place both the hand and the target object under 
a magnifying (or minifying) lens (Linkenauger et al., 2010). Another manipulation has been to differentially render apparent hand size by using virtual reality (see Fig. 7; Linkenauger, Leyrer, Bülthoff, \& Mohler, 2013). In both cases, perceivers estimated object size using a verbal report or a visual matching task (other techniques are described below). For the verbal report, perceivers were given a scale on which 1 corresponded to the size of a pea and 10 corresponded to the size of a basketball. For the visual matching tasks, perceivers viewed two circles on a nearby computer monitor and adjusted the width between the circles to match the width of the target object. The key finding has been that when the hand appears bigger (and thus more capable of grasping larger objects), the target object appears smaller. Several variations of the experiment have tested the six potential pitfalls.

\section{Pitfall \#1: Uniquely disconfirmatory predictions}

If an object is so big that it could not possibly be grasped, it would not make sense for the object to look different depending on the perceiver's hand size. This provides a unique disconfirmatory prediction: Objects too big to be grasped should not look different when the hand appears to be bigger or smaller. The data match this prediction: Hand size impacted the apparent size of objects that could be grasped, but not of objects too big to be grasped (Linkenauger, Witt, \& Proffitt, 2011).

\section{Pitfall \#2: Perception versus judgment}

To assess whether differences in hand size led to differences in perceived object size or simply to differences in judgments of object size, Linkenauger and colleagues (2013) used the indirect measure of perceived shape instead of perceived size. Participants had to indicate whether the shape of a rectangular block was longer or wider prior to grasping the block. The experiment was conducted in virtual reality, and hand size was manipulated by rendering the hand to be larger or smaller than its regular size. Critically, only the width of the hand was manipulated, not its length. This manipulation was expected to impact the perceived object width, but not the perceived object height. Thus, the dependent measure of aspect ratio (rectangle as taller vs. wider) could be used to assess perceived width in particular. When the hand was rendered to be wider, participants judged the shape of the block to be taller than when the hand was rendered to be narrower.

One might argue that aspect ratio in this study was so closely related to object width and that participants were not specifically asked about shape, so perhaps this measure was not truly indirect. However, in another study, the researchers used the perceived weight of the object as an indirect measure of its perceived size (Linkenauger, Mohler, \& Proffitt, 2011). Estimated object weight is influenced by perception of the object's size, as is revealed by the size-weight illusion. In this illusion, objects that are physically larger feel as if they weigh less than similarly weighted but smaller comparison objects. If object size is genuinely perceived to be bigger when the hand is rendered to be smaller, the object should also feel lighter. The data confirmed this prediction. Thus, both direct and indirect measures of object size converge on the same pattern, which provides support for perception as the common underlying process.

\section{Pitfall \#3: Demand and response bias}

Many findings have addressed the issue of whether these effects are due to demand characteristics or response bias. These include the finding that changes in apparent hand size only impact the perception of graspable objects, but not of objects too big to be grasped. One technique was to examine whether

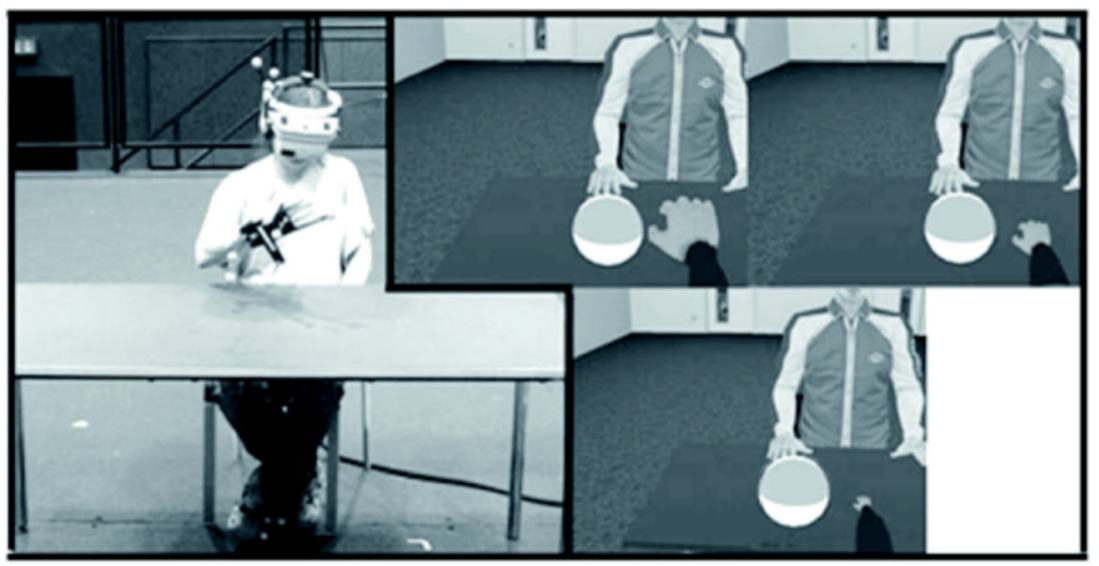

Fig. 7 Virtual reality setup used to manipulate apparent hand size (left). The other panels show participants' views when the hand is rendered as large (top middle), medium (top right), and small (bottom right). From Fig. 1 of "Welcome to Wonderland: The Influence of the Size and Shape of a Virtual Hand on the Perceived Size and Shape of Virtual Objects," by S. A. Linkenauger, M. Leyrer, H. H. Bülthoff, and B. J. Mohler, 2013, PLoS ONE, 8, e68594. Copyright 2013 by Linkenauger et al. Reprinted with permission 
effects on apparent size were also found when the hand was not under the control of the perceiver. This was done by manipulating the size of another person's hands rather than the participant's own hands, or by dissociating the participant's virtual and physical hands by not using motion tracking to track the real hands' motion (Linkenauger et al., 2013; Linkenauger et al., 2010). In these cases, the size of the virtual hand had no impact on the apparent object size. These results provide evidence against a response bias account, because the two conditions (large vs. small virtual hand) would have created a similar response bias in all cases. By showing that the mere rendering of a hand as big or small does not impact the apparent object size, the data effectively rule out a response bias account.

\section{Pitfall \#4: Low-level differences}

A similar argument can be made against an explanation based on low-level visual differences. Low-level visual differences are of utmost concern in these grasping studies, because visual differences in hand size are key to obtaining these effects. Indeed, an intuitively appealing explanation could be that these effects are merely due to cues related to familiar size or to contrast effects. When the familiar object of the hand or a nearby object is larger, target objects look smaller, and vice versa. Such a mechanism could even explain why effects are not found for larger objects, given that the contrast effect would be reduced for the visually-large hand condition (although corresponding contrast effects would be increased for the visually-small hand condition). However, by showing that the same visual information does not lead to similar effects under certain conditions (such as when the hand is not one's own or not under one's control), these results help eliminate an explanation based on familiar size or contrast effects in particular, and low-level differences in general. However, it is possible that these effects could be due to a combination of lowlevel differences and attentional effects (see below), which certainly warrants further testing.

\section{Pitfall \#5: Attentional effects}

Attention is a plausible explanation for this particular actionspecific effect, because prior research has documented effects of attention on size perception (Newsome, 1972). As far as I know, attention has not been directly explored as a critical factor with respect to grasping and perceived object size. Attention is of particular concern because one might also question whether there were differences in the allocation of attention when the virtual hands could versus could not be controlled, and if so, whether these differences in attention led to the different patterns of results across experiments. However, in a similar paradigm in which the entire virtual body was rendered to be large or small, attention did not explain the effect of virtual body size on perceived object size (van der Hoort \& Ehrsson, 2014; van der Hoort, Guterstam, \& Ehrsson, 2011). Participants laid down and saw a virtual body positioned in the same way as their own. The body, however, was rendered to be either twice as big or half as big as their own body size. A virtual box was positioned nearby, and participants had to judge the size of the box. The box was judged to be smaller when the body was rendered bigger than when the body was rendered smaller. In a follow-up experiment to test the role of attention, participants fixated on a central location while an object was placed near their virtual body. If attention was responsible for these effects, equating attention across body size renderings should have eliminated, or at least reduced, the effect of body size on apparent object size. Instead, the effect was just as big as when fixation was not maintained (van der Hoort \& Ehrsson, 2014). Generalizing these results to the grasping study suggests that the influence of grasping on perceived size is not driven by attention. However, more direct studies would be useful. As I stated before, assessing the role of attention is critical for challenging claims related to modularity (Firestone \& Scholl, in press-a), but not for claims related to perceptual experience (Philbeck \& Witt, 2015).

\section{Pitfall \#6: Perception versus memory}

Most judgments were made while the object was within view, making it unlikely that memory-based effects could explain these results.

\section{Summary}

Graspable objects look smaller when the hand appears bigger. These studies rely on magnification lenses or virtual reality to alter hand size, but low-level visual differences cannot account for these effects. Indeed, none of the six pitfalls can account for this effect.

Visual information takes the form of angles - for instance, angular size or disparities between the two eyes, which is also angular. These angles must be transformed by something other than visual information. Proffitt and Linkenauger (2013) proposed that the body provides the ruler necessary to scale angles into the units that perceivers experience. Their proposal differs from similar proposals because they argued that all visual angles are scaled by the body. Others have proposed a role of eye height (determined by the size and position of the body) as a way to scale the angles specifying the distance to objects, the height of objects, and the width of apertures (Sedgwick, 1986; Warren \& Whang, 1987; Wraga, 1999). Proffitt and Linkenauger (2013) proposed that other parts of the body can also be used to scale visual angles. Their proposal has primarily driven their research on hand size and perceived object size, but they argue that this mechanism could 
account for all action-specific effects. Regardless of the mechanism, the results relating hand and object size provide yet another example of a genuine top-down effect of action on perception.

\section{Case Study 4: Anticipated energy required to walk affects perceived distance}

The final case study involves the influence of the anticipated energetics required to walk to a target on the perceived distance to the target. As with all of the case studies, multiple variations of the basic finding have been explored. In one of the original studies, energy was manipulated by having participants wear a backpack and then estimate the distance to targets (Proffitt et al., 2003). This backpack manipulation can be problematic, given that the necessary energy to walk such a short distance (typically 4-8 m) is not much different with and without the backpack. This lack of a difference in physical demands, which is unlikely to produce robust effects in perception, could account for the issues with replicating this particular finding (Hutchinson \& Loomis, 2006; Woods et al., 2009; see Philbeck \& Witt, 2015, for further discussion). Other variations also support the claim that energetic demands influence perceived distance, although I am unaware of any attempts to replicate these findings, and thus they cannot speak to this important issue. These include an effect of wearing ankle weights on estimated gap length (Lessard, Linkenauger, \& Proffitt, 2009), effects of body weight on estimated distance (Sugovic et al., 2016) and estimated slant (Taylor-Covill \& Eves, 2016), and an effect on estimated distance of presenting targets uphill versus on flat ground (Stefanucci, Proffitt, Banton, \& Epstein, 2005). We have begun exploring the latter effect and have found it to be quite robust, but these studies have not yet been vetted by peer review (Tenhundfeld \& Witt, Manuscript under review).

However, one paradigm has been replicated a number of times and has shown repeated effects of anticipated energetic costs on estimated distance. These studies used a treadmill to recalibrate anticipated walking effort (Proffitt et al., 2003; White, Shockley, \& Riley, 2013; Witt et al., 2004; Witt, Proffitt, \& Epstein, 2010). Participants walked on a treadmill for approximately 3-5 min. During this time, participants recalibrated the relationship between forward walking effort and perceived optic flow (Rieser, Pick, Ashmead, \& Garing, 1995). For example, on a regular treadmill, forward walking energy is paired with zero optic flow, so perceivers adapt to the relationship that it takes a lot of effort to go nowhere. Other novel pairings between walking energy and optic flow can be created by using virtual environments (Proffitt et al., 2003; White et al., 2013). Novel pairings can also be created through the clever technique of placing the treadmill on top of a trailer that is being pulled by a tractor (Rieser et al., 1995). This also allows for a complete dissociation between walking speed (determined by the treadmill speed) and optic flow rate (determined by the tractor speed).

By altering the pairing of walking speed and the speed of optic flow, the experience produces a visuomotor adaptation to the new pairing, which results in perceivers anticipating different perceptual outcomes when they walk. For example, after adaptation to optic flow that is too fast, perceivers anticipate more forward movement when they walk, which results in them not walking far enough when they attempt to close their eyes and blindwalk to targets (Rieser et al., 1995). Conversely, when they adapt to optic flow that is too slow, they anticipate more forward movement when they walk, and ultimately walk too far. Similarly, after adapting to optic flow that is too slow, when attempting to walk in place (i.e., with no forward movement), participants end up drifting forward by half a meter. Recalibration to the relationship between walking speed and optic flow speed occurs after just a few minutes of exposure and predicts the outcomes of subsequent actions, including walking, throwing, and kicking (Bruggeman, Pick, \& Rieser, 2005; Bruggeman \& Warren, 2010; Bruggeman, Zosh, \& Warren, 2007; Rieser et al., 1995).

What is additionally remarkable is that this visuomotor adaptation not only impacts subsequent actions, but also subsequent estimates of perceived distance. In the first treadmill experiments designed to assess perceived distance (Proffitt et al., 2003), participants verbally estimated the distances to three targets $(6,8$, and $10 \mathrm{~m}$ away), then walked on a treadmill while viewing a virtual environment that was stationary $(0$ mph) or was moving at the same speed as the treadmill (3 mph). Afterward, participants were blindfolded and led back to the hallway for one final distance estimate to a target placed $8 \mathrm{~m}$ away. The final estimate was divided by the preadaptation estimate to compute a ratio score. Participants in the 0 -mph optic flow condition had a higher ratio score than did participants in the 3-mph optic flow condition. This suggests that targets appeared farther away for those who recalibrated to the new relationship between walking energy and distance traversed.

\section{Pitfall \#1: Uniquely disconfirmatory predictions}

Early on it was discovered that action-specific effects could be modulated by the perceiver's intention to act (Witt et al., 2004). Effort for walking influenced perceptual judgments of distance for perceivers who intended to walk, but not for perceivers who intended to throw. In one study, participants verbally estimated the distance to targets placed at 6,8 , and $10 \mathrm{~m}$. After each estimate, one group of participants closed their eyes and threw a beanbag to the target. Another group closed their eyes and walked to the target. Thus, one group viewed the targets with the intention to throw, and another group with the intention to walk. Both groups then walked 
on a treadmill. Virtual reality was not used, so all participants experienced forward walking effort paired with zero optic flow. After recalibrating to this new relationship, participants viewed a test target (at $8 \mathrm{~m}$ ), verbally estimated its distance, and performed the same action that they had prior to walking on the treadmill. As before, ratio scores were calculated. The group that intended to blindwalk estimated the targets to be farther away after the treadmill adaptation than did the group that intended to throw. In other words, the recalibrating effort for walking influenced the perceived distance for those who intended to walk, but not for those who intended to throw. The lack of an effect of the treadmill on participants who intended to throw serves as a uniquely disconfirmatory finding. Walking on a treadmill does not always lead to increases in estimated distance; instead, the effect depends on the perceiver's intention to act.

Although this is one piece of evidence for a uniquely disconfirmatory prediction, the paradigm is well suited to be applied to the El Greco suggestion (Firestone \& Scholl, 2014). The El Greco suggestion is to use the a visual matching task that in which the target and matching objects would be equally likely to be affected by a perceptual effect as the target object. If the effect is perceptual, the effect it should be of a similar magnitudes on both the target and the matched objects, thereby canceling out the effect and producing a null (uniquely disconfirmatory) finding. If the effect is due to a non-perceptual effects cause, such as response bias, the effecit should still emerge as significant. In the case of the treadmill studies, after walking on a treadmill, participants could adjust the position of one cone to match the distance to a target cone presented in an opposite direction. Any effect of the treadmill on the perceived distance to the target cone should also affect the perceived distance to the comparison cone, thus resulting in the predicted null effect. If, instead, participants positioned the comparison cone to be farther away, this would be evidence against a perceptual effect. In doing such a study, it would be important to counterbalance the positions of the target and comparison cones, due to context effects (Lappin, Shelton, \& Rieser, 2006; Witt et al., 2007), and it would also be important to counterbalance the starting position of the comparison cone as near versus far (Witt et al., 2004). In addition, it might also be useful to control for intention: If participants were to view only the target cone with the intention to walk, it is possible that the treadmill manipulation could impact the perceived distance to the target but not to the comparison cone. In this case, the data could not be used to separate an $\mathrm{El} \mathrm{Greco} \mathrm{account} \mathrm{from} \mathrm{a} \mathrm{perceptual} \mathrm{account.} \mathrm{A} \mathrm{simple} \mathrm{fix}$ would be to instruct participants that they would blindwalk to one of the two cones, and the cone would be indicated after they had closed their eyes. Such instructions would help ensure that participants viewed both cones with the intention to walk.

\section{Pitfall \#2: Perception versus judgment}

As was stated earlier, the technique valued most by the literature on distance perception for separating perception from judgment is the use of converging measures (Foley, 1977; Gogel, 1990; Loomis \& Philbeck, 2008; Philbeck \& Loomis, 1997). Thus, to address the issue of whether walking energy impacts perceived distance, or merely judgments of distance, studies have been run using either verbal estimates (Proffitt et al., 2003; Witt et al., 2004) or measures for which no explicit judgment is made. Instead, participants estimate distance by reproducing the distance by blindwalking to the target (White et al., 2013; Witt, Proffitt, \& Epstein, 2010).

In the first experiment to manipulate the intention and anticipated effort for walking, participants verbally estimated the distance to the targets, and the researchers found that those who intended to walk estimated the targets as being farther away than those who intended to throw (Witt et al., 2004). In a variation of this experiment, participants were again divided into those who intended to throw and those who intended to walk (Witt, Proffitt, \& Epstein, 2010). Participants were given instructions about which action they would perform, walked on a treadmill with 0 -mph optic flow, and then viewed a target placed $8 \mathrm{~m}$ away (see Fig. 8). When ready, all participants donned a blindfold as they readied themselves to perform the assigned action of blindwalking or blind throwing. At this point, we instructed those who had intended to throw that they should walk to the target instead. They were not given a second opportunity to view the target. We measured the blindwalked distance as the estimate of perceived distance. Note that all participants experienced walking on the treadmill with zero optic flow and all participants blindwalked to the target, and that the only difference was their intention at the time they viewed the target. The group that had intended to walk blindwalked farther than did those who intended to throw. Importantly, these group differences were not found when the treadmill manipulation was not used, verifying that the group differences were not due to a change in the intended action for one group and not the other. Instead, the differences in blindwalked distance reflect differences in the perceived distance to the target. This demonstrates the actionspecific effect of anticipated effort on perceived distance across converging measures.

In another study, participants received one of three treadmill manipulations: walking speed increased, optic flow decreased, or grade of incline increased (or vice versa, for each). Participants then had to reproduce the perceived distance by walking that same extent as the target distance (White et al., 2013). When the energy required to walk increased, participants walked farther than when the energy to walk decreased. Again, differences in perceived distance were revealed using blindwalking. This study also suggests that because all three ways of manipulating energy were equivalent in their effects on apparent distance, a single underlying factor specified the energy. White et al. termed this variable the multimodally specified energy expenditure. Their results suggest that perceivers can detect and use this variable when perceiving distance. 


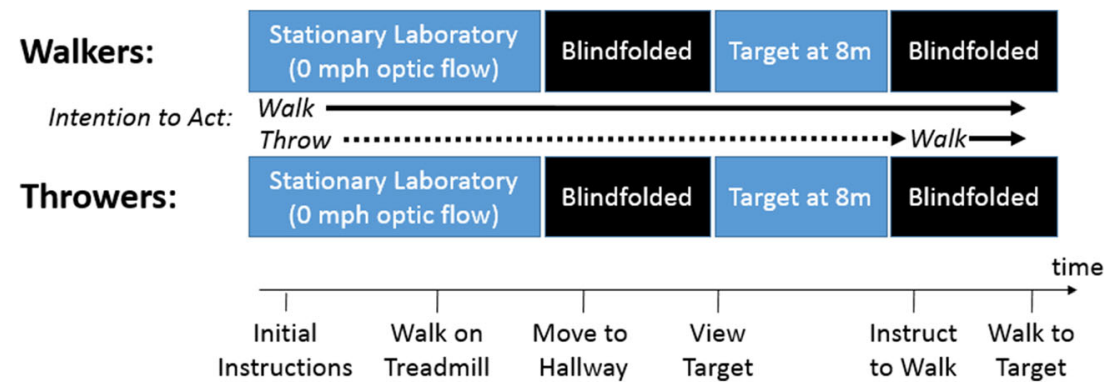

Fig. 8 Overview of visual information (in boxes) and intention (in italics) over the course of the experiment (timeline on the bottom) for a group of participants who intend to walk (walkers) and a group who intend to throw (throwers). Note that the visual information is the same

\section{Pitfall \#3: Demand and response bias}

The treadmill manipulation is particularly useful, because it is not obvious that objects should appear farther after walking on a treadmill. We recently conducted a survey of 47 participants and asked whether walking on a treadmill should make targets look closer, farther, or not impact their perception of distance. ${ }^{3}$ Only $13(28 \%)$ correctly stated farther, $12(25 \%)$ stated no impact, and 22 (47\%) indicated the opposite prediction, that the targets should appear closer (Witt \& Tenhundfeld, Manuscript in preparation). That so few people guessed correctly, and that many more guessed the opposite prediction, strongly suggests that response bias is unlikely to account for these results (and might even reduce the true size of the perceptual effect). Moreover, the studies on intention also speak against a response bias explanation, because both groups of participants had the same treadmill experience. Had participants felt pressure to respond that the targets appeared farther after walking on a treadmill, both groups should have estimated the distances as being farther, because both groups had walked on the treadmill. Had participants felt pressure to respond that the targets appeared farther away when they intended to walk than when they intended to throw, we would not have found increased estimates of distance for those who intended to throw after throwing a heavy ball, as compared with those who intended to walk after throwing the heavy ball (Witt et al., 2004). The subtle nuances involved in the interaction between effort and intention are unlikely to be explained using a response bias account, yet they are predicted by the action-specific account.

\section{Pitfall \#4: Low-level differences}

In the case of the experiments in which intention to act, rather than optic flow, was manipulated, the visual information at the time that the judgments were made (or at the time the target was viewed prior to blindwalking) was always the same across conditions in all

\footnotetext{
$\overline{3}$ Participants were given a description of the experiment and four response options: closer, farther, no impact, or other, with the opportunity to write in a response (which no one did).
}

for both groups and that during the time that each group views the target, the only aspect that differs is their intention to act. Both groups blindwalk to the target, and their blindwalking distance is taken as a measure of the perceived distance (details are from Witt et al., 2010)

experiments (see Fig. 8). This fact thereby rules out this potential pitfall. It is possible that adaptation to the treadmill led to differences in processing of the visual information, but these differences would be consistent across both intention conditions, and thus cannot account for the differences in the estimated or blindwalked distance between people who intended to throw and those who intended to walk (Witt et al., 2004; Witt, Proffitt, \& Epstein, 2010).

\section{Pitfall \#5: Attentional effects}

Attention has not been specifically addressed with respect to energetics and perceived distance. Perhaps people attend to the target differently when they anticipate walking versus throwing, or perhaps they attend differently when they anticipate that walking will be harder than when it will be easier. In the former case attention seems unlikely to be the critical factor, given that we have demonstrated a double dissociation, with intention only increasing estimated distance when effort is also manipulated (Witt et al., 2004; Witt, Proffitt, \& Epstein, 2010). In the latter case attention is a possible explanation, given that it has not been formally measured in this context. However, previous research suggests that attention is unlikely to impact perceived distance in a similar range. Philbeck (2000) manipulated attention by allowing only a single fixation to a specific distance on each trial (which sometimes corresponded to the target distance and at other times corresponded to nontarget distances), or by allowing free viewing. He found no differences in estimated distance (via a blindwalking task) to fixated target distances, nonfixated distances, and distances viewed without constraints on fixations. Given that such strong manipulations of fixation (forced single fixation to a location 1-2 $\mathrm{m}$ away vs. forced single fixation to the target vs. unconstrained fixations) produced no differences in estimated distances, it is unlikely that any differences in attention caused by effort manipulations could have led to the 1-m effects observed in the action-specific studies.

\section{Pitfall \#6: Perception versus memory}

It is somewhat surprising that the measure of blindwalking is taken as a compelling measure of perception, given that the 
perceiver's eyes are closed. Perhaps this raises the concern that studies involving blindwalking tasks tapped into effects on memory rather than perception. However, blindwalking has always been considered to be a perceptual measure, in part because it is one of the most accurate measures of perceived distance (Loomis et al., 1992). Furthermore, studies using verbal reports have revealed the same patterns as with blindwalking, and the target is clearly within view during verbal judgments of distance. Perhaps action-specific effects could be further exaggerated in memory, but both types of studies have revealed similar magnitudes of effects, which is inconsistent with the idea of increased effects in memory.

\section{Summary}

The anticipated energetic costs associated with walking influence the perceived distance to targets. In many studies, a treadmill manipulation was used to manipulate the anticipated effort for walking, because the treadmill leads to a recalibration between forward walking energy and the anticipated perceptual outcome (Rieser et al., 1995). After walking on a treadmill, perceivers see targets to be farther away, as assessed with the converging measures of verbal estimates and blindwalking (Proffitt et al., 2003; White et al., 2013; Witt et al., 2010).

\section{Rejecting modularity while keeping cognitive impenetrability}

The data show that a person's ability to act—including blocking, reaching, grasping, and walking - influences spatial perception. In the case of blocking, the first case study above decisively rejects the claim that it exerts no top-down effects on perception (cf. Firestone \& Scholl, in press-a). In the case of grasping and walking, both direct and indirect evidence also provide compelling cases for top-down effects on perception. In the case of reaching, empirical evidence is still needed for the attentionrelated pitfall, since all other pitfalls have been addressed. Nevertheless, sufficient evidence has been presented to assert that top-down influences can influence spatial perception.

The claim that top-down factors can influence spatial perception depends on the definition of top-down. A strict definition would be that any effect not based on visual information is an example of a top-down effect. Firestone and Scholl (in press-a) already rejected this definition through their acceptance of crossmodal effects and their acceptance of the role of natural constraints.

A narrower definition of top-down effects could be those based on cognitive knowledge. In this case, a top-down effect would require that the perceiver's explicit knowledge about a particular thing influence perception. According to this definition, actionspecific effects would not qualify as top-down effects, because action-specific effects are based on motor, not cognitive, processes (Sugovic et al., 2016; Taylor-Covill \& Eves, 2016; Witt \& Dorsch, 2009; Witt et al., 2008; Witt \& Proffitt, 2008; Witt et al., 2014). Thus, one can accept action-specific effects as being perceptual without having to reject the idea that spatial perception is immune to cognitive influence. In other words, action-specific effects discredit the idea of modularity and its claim that action is not able to influence perception. But actionspecific effects do not challenge the idea that perception is cognitively impenetrable.

It might seem that arguing for a role of intention as being critical is also arguing for a role for cognition, given that intention and cognition seem related. However, I have never argued that intention impacts perception directly. Rather, intention plays the role of selector, in that it selects the information about action that is relevant at any given time. Thus, the role of intention is indirect. A good analogy is that intention is similar to attention as it was discussed by Firestone and Scholl (in press-a); both can impact perceptual experience, but neither does so by directly influencing or informing perceptual processes. Rather, they change the information that is processed by perception.

It is important to state that providing these four case studies does not mean that these are the only genuine action-specific effects. Many other effects are likely to be genuine, but they do not yet have a sufficient quantity of systematic research that can address all six pitfalls. For example, the relationship between athletic performance and perceived size has been documented in myriad sports. Several pitfalls have been examined, such as accounting for memory-based effects (Witt et al., 2008), low-level differences (Witt \& Dorsch, 2009), and attention (Gray et al., 2014). But other pitfalls still need to be explored. As another example, the influence of the energetic demands of ascending a hill or a staircase on estimated slant has been explored with respect to response bias (Bhalla \& Proffitt, 1999; Taylor-Covill \& Eves, 2013, 2014, 2016); the pitfalls related to low-level differences and memory are irrelevant, given the nature of the tasks, but the other pitfalls have yet to be explored. The six-pitfall framework provides direction for filling gaps in the literature, and surely more effects than these four case studies will be discovered and properly evaluated.

Some scholars still cling to the idea that the mind is modular (Firestone \& Scholl, in press-a; Pylyshyn, 2003). However, an increasing number of scientists have come to understand that perceptual processes are inherently linked to action. Action-perception relationships have been demonstrated in a wide number of research fields, including the perception of biological motion (e.g., Grosjean, Shiffrar, \& Knoblich, 2007; Shiffrar \& Freyd, 1990; for a review, see van der Wel, Sebanz, \& Knoblich, 2013), the visual selection and organization of information (Bekkering \& Neggers, 2002; Cosman \& Vecera, 2010; Guetteling, Kenemans, \& Neggers, 2011; Huffman, Gozli, Welsh, \& Pratt, 2015; Thomas, 2015), 
the perception of features, objects, and tools (Hommel, Müsseler, Aschersleben, \& Prinz, 2001; Müsseler \& Hommel, 1997; Symes, Tucker, Ellis, Vainio, \& Ottoboni, 2008; Witt, Kemmerer, Linkenauger, \& Culham, 2010), and auditory perception (Repp \& Knoblich, 2007; Schutz \& Lipscomb, 2007). The action-specific account of perception demonstrates yet another relationship: that a person's ability to perform an intended action influences spatial perception itself.

Author note The author thanks Nate Tenhundfeld, Marcos Janzen, Zach King, Chaz Firestone, Brian Scholl, Greg Hickok, and Dan Simons for their thoughtful and useful discussions and feedback. This work was supported by grants from the National Science Foundation (Nos. BCS-1348916 and BCS-1632222).

\section{References}

Aubert, H. (1886). Die Bewegungsempfindung [The sensation of movement]. Pflügers Archiv, 39, 347-370.

Bekkering, H., \& Neggers, S. F. W. (2002). Visual search is modulated by action intentions. Psychological Science, 13, 370-374. doi:10.1111/j.09567976.2002.00466.x

Bhalla, M., \& Proffitt, D. R. (1999). Visual-motor recalibration in geographical slant perception. Journal of Experimental Psychology: Human Perception and Performance, 25, 1076-1096. doi:10.1037/00961523.25.4.1076

Bloesch, E. K., Davoli, C. C., Roth, N., Brockmole, J. R., \& Abrams, R. A. (2012). Watch this! Observed tool use affects perceived distance. Psychonomic Bulletin \& Review, 19, 177-183. doi:10.3758/s13423011-0200-Z

Bruggeman, H., Pick, H. L., Jr., \& Rieser, J. J. (2005). Learning to throw on a rotating carousel: Recalibration based on limb dynamics and projectile kinematics. Experimental Brain Research, 163, 188-197.

Bruggeman, H., \& Warren, W. H. (2010). The direction of walking-but not throwing or kicking - is adapted by optic flow. Psychological Science, 21, 1006-1013. doi:10.1177/0956797610372635

Bruggeman, H., Zosh, W., \& Warren, W. H. (2007). Optic flow drives human visuo-locomotor adaptation. Current Biology, 17, 20352040. doi:10.1016/j.cub.2007.10.059

Canal-Bruland, R., Pijpers, J. R., \& Oudejans, R. R. (2010). The influence of anxiety on action-specific perception. Anxiety, Stress, and Coping, 23, 353-361.

Carson, V. R. (1977). Instructions and perceptual constancy judgments. In W. Epstein (Ed.), Stability and constancy in visual perception: Mechanisms and processes (pp. 217-254). New York, NY: Wiley.

Chauvel, G., Wulf, G., \& Maquestiaux, F. (2015). Visual illusions can facilitate sport skill learning. Psychonomic Bulletin \& Review, 22, 717-721.

Choe, C. S., Welch, R. B., Gilford, R. M., \& Juola, J. F. (1975). The "ventriloquist effect": Visual dominance or response bias? Perception \& Psychophysics, 18, 55-60. doi:10.3758/BF03199367

Cosman, J. D., \& Vecera, S. P. (2010). Attention affects visual perceptual processing near the hand. Psychological Science, 21, 1254-1258. doi: $10.1177 / 0956797610380697$

Costello, M. C., Bloesch, E. K., Davoli, C. C., Panting, N. D., Abrams, R. A., \& Brockmole, J. R. (2015). Spatial representations in older adults are not modified by action: Evidence from tool use. Psychology and Aging, 30, 656-668. doi:10.1037/pag0000029

Davoli, C. C., Brockmole, J. R., \& Witt, J. K. (2012). Compressing perceived distance with remote tool-use: real, imagined, and remembered. Journal of Experimental Psychology: Human Perception and Performance, 38, 80-89. doi:10.1037/A0024981
Durgin, F. H., Baird, J. A., Greenburg, M., Russell, R., Shaughnessy, K., \& Waymouth, S. (2009). Who is being deceived? The experimental demands of wearing a backpack. Psychonomic Bulletin \& Review, 16, 964-969. doi:10.3758/PBR.16.5.964

Durgin, F. H., Klein, B., Spiegel, A., Strawser, C. J., \& Williams, M. (2012). The social psychology of perception experiments: Hills, backpacks, glucose, and the problem of generalizability. Journal of Experimental Psychology: Human Perception and Performance, 38, 1582-1595.

Firestone, C. (2013). How "paternalistic" is spatial perception? Why wearing a heavy backpack doesn't — and couldn't - make hills appear steeper. Perspectives on Psychological Science, 8, 455-473.

Firestone, C., \& Scholl, B. J. (2014). "Top-down" effects where none should be found: The El Greco fallacy in perception research. Psychological Science, 25(1), 38-46.

Firestone, C., \& Scholl, B. J. (2015). When do ratings implicate perception versus judgment? The "overgeneralization test" for top-down effects. Visual Cognition, 23, 1217-1226. doi:10.1080/13506285.2016.1160171

Firestone, C., \& Scholl, B. J. (in press-a). Cognition does not affect perception: Evaluating the evidence for "top-down" effects. Behavioral and Brain Sciences. doi:10.1017/S0140525X15000965

Firestone, C., \& Scholl, B. J. (in press-b). Seeing and thinking: Foundational issues and empirical horizons [response to commentators]. Behavioral and Brain Sciences.

Fleischl, E. V. (1882). Physiologisch-optische Notizen, 2. Mittheilung [Physiologically optical notes, second notification]. Sitzungsberichte der Akademie der Wissenschaften, 86, 7-25.

Foley, J. M. (1977). Effect of distance information and range on two indices of visually perceived distance. Perception, 6, 449-460.

Gibson, J. J. (1979). The ecological approach to visual perception. Boston, MA: Houghton Mifflin.

Gogel, W. C. (1969). The sensing of retinal size. Vision Research, 9 , 1079-1094.

Gogel, W. C. (1990). A theory of phenomenal geometry and its applications. Perception \& Psychophysics, 48, 105-123.

Gogel, W. C., \& Tietz, J. D. (1977). Eye fixation and attention as modifiers of perceived distance. Perceptual and Motor Skills, 45, 343-362.

Gray, R. (2013). Being selective at the plate: Processing dependence between perceptual variables relates to hitting goals and performance. Journal of Experimental Psychology: Human Perception and Performance, 39, 1124-1142. doi:10.1037/a0030729

Gray, R. (2016). Better understanding of the link between embodied perception and behavior needed before we can apply it. Journal of Applied Research in Memory and Cognition, 5, 86-87.

Gray, R., Navia, J. A., \& Allsop, J. (2014). Action-specific effects in aviation: What determines judged runway size? Perception, 43, $145-154$

Grèzes, J., \& Decety, J. (2001). Functional anatomy of execution, mental simulation, observation, and verb generation of actions: A metaanalysis. Human Brain Mapping, 12, 1-19. doi:10.1002/10970193(200101)12:1<1::AID-HBM10>3.0.CO;2-V

Grosjean, M., Shiffrar, M., \& Knoblich, G. (2007). Fitts's law holds for action perception. Psychological Science, 18, 95-99. doi:10.1111 j. 1467-9280.2007.01854.x

Grove, P. M., Ashton, J., Kawachi, Y., \& Sakurai, K. (2012). Auditory transients do not affect visual sensitivity in discriminating between objective streaming and bouncing events. Journal of Vision, 12(8), 5:1-11. doi:10.1167/12.8.5

Guetteling, T. P., Kenemans, J. L., \& Neggers, S. F. W. (2011). Grasping preparation enhances orientation change detection. PLoS ONE, 6, e17675. doi:10.1371/journal.pone.0017675

Hommel, B., Müsseler, J., Aschersleben, G., \& Prinz, W. (2001). The Theory of Event Coding (TEC): A framework for perception and action planning. Behavioral and Brain Sciences, 24, 849-878, disc. 878-937. doi:10.1017/S0140525X01000103 
Huffman, G., Gozli, D. G., Welsh, T. N., \& Pratt, J. (2015). Hand position influences perceptual grouping. Experimental Brain Research, 233, $2627-2634$

Hutchinson, J. J., \& Loomis, J. M. (2006). Does energy expenditure affect the perception of egocentric distance? A failure to replicate Experiment 1 of Proffitt, Stefanucci, Banton, and Epstein (2003). Spanish Journal of Psychology, 9, 332-339.

Kilner, J. M., Paulignan, Y., \& Blakemore, S. J. (2003). An interference effect of observed biological movement on action. Current Biology, $13,522-525$.

King, Z. R., Tenhundfeld, N. T., \& Witt, J. K. (2015). An action-specific perception effect that withstands feedback. Journal of Vision, 15(12), 594. doi: $10.1167 / 15.12 .594$

King, Z. R., Tenhundfeld, N. T., \& Witt, J. K. (2016). What you see and what you are told: Feedback does not diminish action-specific perception. Manuscript under review.

Lappin, J. S., Shelton, A. L., \& Rieser, J. J. (2006). Environmental context influences visually perceived distance. Perception \& Psychophysics, 68, 571-581. doi:10.3758/BF03208759

Lee, Y., Lee, S., Carello, C., \& Turvey, M. T. (2012). An archer's perceived form scales the "hitableness" of archery targets. Journal of Experimental Psychology: Human Perception and Performance, $38,1125-1131$

Lessard, D. A., Linkenauger, S. A., \& Proffitt, D. R. (2009). Look before you leap: Jumping ability affects distance perception. Perception, $38,1863-1866$.

Linkenauger, S. A., Bülthoff, H. H., \& Mohler, B. J. (2015). Virtual arm's reach influences perceived distance but only after experience reaching. Neuropsychologia, 70, 393-401. doi:10.1016/j. neuropsychologia.2014.10.034

Linkenauger, S. A., Leyrer, M., Bülthoff, H. H., \& Mohler, B. J. (2013). Welcome to Wonderland: The influence of the size and shape of a virtual hand on the perceived size and shape of virtual objects. PLoS ONE, 8, e68594. doi:10.1371/journal.pone.0068594

Linkenauger, S. A., Mohler, B. J., \& Proffitt, D. R. (2011). Body-based perceptual rescaling revealed through the size-weight illusion. Perception, 40, 1251-1253. doi:10.1068/P7049

Linkenauger, S. A., Ramenzoni, V., \& Proffitt, D. R. (2010). Illusory shrinkage and growth: Body-based rescaling affects the perception of size. Psychological Science, 21, 1318-1325. doi:10.1177/0956797610380700

Linkenauger, S. A., Witt, J. K., \& Proffitt, D. R. (2011). Taking a handson approach: Apparent grasping ability scales the perception of object size. Journal of Experimental Psychology: Human Perception and Performance, 37, 1432-1441. doi:10.1037/a0024248

Loomis, J. M. (2016). Proposed applications of research on actionspecific effects are premature. Journal of Applied Research in Memory and Cognition, 5, 77-79.

Loomis, J. M., da Silva, J. A., Fujita, N., \& Fukusima, S. S. (1992). Visual space perception and visually directed action. Journal of Experimental Psychology: Human Perception and Performance, 18, 906-921. doi:10.1037/0096-1523.18.4.906

Loomis, J. M., \& Philbeck, J. W. (2008). Measuring perception with spatial updating and action. In R. L. Klatzky, M. Behrmann, \& B. MacWhinney (Eds.), Embodiment, ego-space, and action (pp. 144). Mahwah, NJ: Erlbaum.

Milner, A. D., \& Goodale, M. A. (1995). The visual brain in action. New York, NY: Oxford University Press.

Milner, A. D., \& Goodale, M. A. (2008). Two visual systems re-viewed. Neuropsychologia, 46, 774-785. doi:10.1016/j. neuropsychologia.2007.10.005

Müsseler, J., \& Hommel, B. (1997). Blindness to response-compatible stimuli. Journal of Experimental Psychology: Human Perception and Performance, 23, 861-872. doi:10.1037/0096-1523.23.3.861

Newsome, L. R. (1972). Visual angle and apparent size of objects in peripheral vision. Perception \& Psychophysics, 12, 300-304.
Ooi, T. L., Wu, B., \& He, Z. J. (2006). Perceptual space in the dark affected by the intrinsic bias of the visual system. Perception, 35 605-624.

Orne, M. T. (1682). On the social psychology of the psychological experiment: With particular reference to demand characteristics and their implications. American Psychologist, 17, 776-783.

Osiurak, F., Morgado, N., \& Palluel-Germain, R. (2012). Tool use and perceived distance: When unreachable becomes spontaneously reachable. Experimental Brain Research, 218, 331-339. doi:10.1007/s00221-012-3036-5

Palmer, J., Verghese, P., \& Pavel, M. (2000). The psychophysics of visual search. Vision Research, 40, 1227-1268.

Philbeck, J. W. (2000). Visually directed walking to briefly glimpsed targets is not biased toward fixation location. Perception, 29, 259-272.

Philbeck, J. W., \& Loomis, J. M. (1997). Comparison of two indicators of visually perceived egocentric distance under full-cue and reducedcue conditions. Journal of Experimental Psychology: Human Perception and Performance, 23, 72-85. doi:10.1037/00961523.23.1.72

Philbeck, J. W., \& Witt, J. K. (2015). Action-specific influences on perception and post-perceptual processes: Present controversies and future directions. Psychological Bulletin, 141, 1120-1144. doi: $10.1037 / \mathrm{a} 0039738$

Poulton, E. C. (1979). Models for biases in judging sensory magnitude. Psychological Bulletin, 86, 777-803.

Proffitt, D. R., \& Linkenauger, S. A. (2013). Perception viewed as a phenotypic expression. In W. Prinz, M. Beisert, \& A. Herwig (Eds.), Action science: Foundations of an emerging discipline (pp. 171-198). Cambridge, MA: MIT Press.

Proffitt, D. R., Stefanucci, J., Banton, T., \& Epstein, W. (2003). The role of effort in perceiving distance. Psychological Science, 14, 106-112.

Pylyshyn, Z. W. (2003). Seeing and visualizing: It's not what you think. Cambridge, MA: MIT Press.

Ramachandran, V. S. (1988). Perception of shape from shading. Nature, 331, 163-166. doi:10.1038/331163a0

Repp, B. H., \& Knoblich, G. (2007). Action can affect auditory perception. Psychological Science, 18, 6-7.

Rieser, J. J., Pick, H. L., Ashmead, D. H., \& Garing, A. E. (1995). Calibration of human locomotion and models of perceptual-motor organization. Journal of Experimental Psychology: Human Perception and Performance, 21, 480-497. doi:10.1037/00961523.21.3.480

Rosenbaum, D. A. (2005). The Cinderella of psychology: The neglect of motor control in the science of mental life and behavior. American Psychologist, 60, 308-317.

Rosenthal, O., Shimojo, S., \& Shams, L. (2009). Sound-induced flash illusion is resistant to feedback training. Brian Topography, 21, 185 192. doi:10.1007/s10548-009-0090-9

Schutz, M., \& Lipscomb, S. (2007). Hearing gestures, seeing music: Vision influences perceived tone duration. Perception, 36, 888-897.

Sedgwick, H. (1986). Space perception. In K. R. Boff, L. Kaufman, \& J. P. Thomas (Eds.), Handbook of perception and human performance (Vol. 1, pp. 1-57). New York, NY: Wiley.

Shaffer, D. M., McManama, E., Swank, C., \& Durgin, F. H. (2013). Sugar and space? Not the case: Effects of low blood glucose on slant estimation are mediated by beliefs. i-Perception, 4, 147-155.

Shams, L., \& Kim, R. (2010). Crossmodal influences on visual perception. Physics of Life Reviews, 7, 269-284.

Shiffrar, M., \& Freyd, J. (1990). Apparent motion of the human body. Psychological Science, 1, 257-264.

Shimojo, S., \& Shams, L. (2001). Sensory modalities are not separate modalities: Plasticity and interactions. Current Opinion in Neurobiology, 11, 505-509.

Stefanucci, J. K., Proffitt, D. R., Banton, T., \& Epstein, W. (2005). Distances appear different on hills. Perception \& Psychophysics, 67, 1052-1060. 
Sugovic, M., Turk, P., \& Witt, J. K. (2016). Perceived distance and obesity: It's what you weigh, not what you think. Acta Psychologica, 165, 1-8. doi:10.1016/j.actpsy.2016.01.012

Symes, E., Tucker, M., Ellis, R., Vainio, L., \& Ottoboni, G. (2008). Grasp preparation improves change detection for congruent objects. Journal of Experimental Psychology: Human Perception and Performance, 34, 854-871. doi:10.1037/0096-1523.34.4.854

Taylor, J. E. T., Witt, J. K., \& Sugovic, M. (2011). When walls are no longer barriers: Perception of wall height in parkour. Perception, 40, 757-760. doi:10.1068/P6855

Taylor-Covill, G. A. H., \& Eves, F. F. (2013). Slant perception for stairs and screens: Effects of sex and fatigue in a laboratory environment. Perception, 42, 459-469.

Taylor-Covill, G. A. H., \& Eves, F. F. (2014). When what we need influences what we see: Choice of energetic replenishment is linked with perceived steepness. Journal of Experimental Psychology: Human Perception and Performance, 40, 915-919. doi:10.1037/a0036071

Taylor-Covill, G. A. H., \& Eves, F. F. (2016). Carrying a biological "backpack": Quasi-experimental effects of weight status and body fat change on perceived steepness. Journal of Experimental Psychology: Human Perception and Performance, 42, 331-338. doi: $10.1037 / \mathrm{xhp} 0000137$

Thomas, L. E. (2015). Grasp posture alters visual processing biases near the hands. Psychological Science, 26, 625-632.

Treisman, A. (1982). Perceptual grouping and attention in visual search for features and for objects. Journal of Experimental Psychology: Human Perception and Performance, 8, 194-214. doi:10.1037/00961523.8.2.194

Trommershäuser, J., Maloney, L. T., \& Landy, M. S. (2008). Decision making, movement planning, and statistical decision theory. Trends in Cognitive Sciences, 12, 291-297. doi:10.1016/j.tics.2008.04.010

van der Hoort, B., \& Ehrsson, H. H. (2014). Body ownership affects visual perception of object size by rescaling the visual representation of external space. Attention, Perception, \& Psychophysics, 76, 1414-1428. doi:10.3758/s13414-014-0664-9

van der Hoort, B., Guterstam, A., \& Ehrsson, H. H. (2011). Being Barbie: The size of one's own body determines the perceived size of the world. PLoS ONE, 6, e20195. doi:10.1371/journal.pone.0020195

van der Wel, R. P. R. D., Sebanz, N., \& Knoblich, G. (2013). Action perception from a common coding perspective. In K. L. Johnson \& M. Shiffrar (Eds.), People watching: Social, perceptual, and neurophysiological studies of body perception (pp. 101-120). New York, NY: Oxford University Press.

Warren, W. H., \& Whang, S. (1987). Visual guidance of walking through apertures: Body-scaled information for affordances. Journal of Experimental Psychology: Human Perception and Performance, 13, 371-383. doi:10.1037/0096-1523.13.3.371

Wesp, R., Cichello, P., Gracia, E. B., \& Davis, K. (2004). Observing and engaging in purposeful actions with objects influences estimates of their size. Perception \& Psychophysics, 66, 1261-1267. doi:10.3758/BF03194996

Wesp, R., \& Gasper, J. (2012). Is size misperception of targets simply justification for poor performance? Perception, 41, 994-996. doi: $10.1068 / \mathrm{p} 7281$

White, E., Shockley, K., \& Riley, M. A. (2013). Multimodally specified energy expenditure and action-based distance judgments. Psychonomic Bulletin \& Review, 20, 1371-1377. doi:10.3758/s13423-013-0462-8

Witt, J. K. (2011). Tool use influences perceived shape and perceived parallelism, which serve as indirect measures of perceived distance. Journal of Experimental Psychology: Human Perception and Performance, 37, 1148-1156. doi:10.1037/a0021933

Witt, J. K. (2015). Awareness is not a necessary characteristic of a perceptual effect: Commentary on Firestone (2013). Perspectives on Psychological Science, 10, 865-872.
Witt, J. K., \& Dorsch, T. E. (2009). Kicking to bigger uprights: Field goal kicking performance influences perceived size. Perception, 38, 1328-1340. doi:10.1068/P6325

Witt, J. K., Kemmerer, D., Linkenauger, S. A., \& Culham, J. (2010). A functional role for motor simulation in identifying tools. Psychological Science, 21, 1215-1219. doi:10.1177 /0956797610378307

Witt, J. K., Linkenauger, S. A., Bakdash, J. Z., \& Proffitt, D. R. (2008). Putting to a bigger hole: Golf performance relates to perceived size. Psychonomic Bulletin \& Review, 15, 581-585. doi:10.3758/15.3.581

Witt, J. K., Linkenauger, S. A., \& Proffitt, D. R. (2012). Get me out of this slump! Visual illusions improve sports performance. Psychological Science, 23, 397-399. doi:10.1177/0956797611428810

Witt, J. K., Linkenauger, S. A., \& Wickens, C. D. (2016). Action-specific effects in perception and their potential applications: A reply to commentaries. Journal of Applied Research in Memory and Cognition, 5, 88-93.

Witt, J. K., \& Proffitt, D. R. (2005). See the ball, hit the ball-Apparent ball size is correlated with batting average. Psychological Science, 16, 937-938. doi:10.1111/j.1467-9280.2005.01640.x

Witt, J. K., \& Proffitt, D. R. (2008). Action-specific influences on distance perception: A role for motor simulation. Journal of Experimental Psychology: Human Perception and Performance, 34, 1479-1492. doi:10.1037/a0010781

Witt, J. K., Proffitt, D. R., \& Epstein, W. (2004). Perceiving distance: A role of effort and intent. Perception, 33, 577-590. doi:10.1068 /P5090

Witt, J. K., Proffitt, D. R., \& Epstein, W. (2005). Tool use affects perceived distance, but only when you intend to use it. Journal of Experimental Psychology: Human Perception and Performance, 31, 880-888. doi:10.1037/0096-1523.31.5.880

Witt, J. K., Proffitt, D. R., \& Epstein, W. (2010). When and how are spatial perceptions scaled? Journal of Experimental Psychology: Human Perception and Performance, 36, 1153-1160. doi:10.1037 /A0019947

Witt, J. K., \& Riley, M. A. (2014). Discovering your inner Gibson: Reconciling action-specific and ecological approaches to perception-action. Psychonomic Bulletin \& Review, 21, 1353-1370.

Witt, J. K., Schuck, D. M., \& Taylor, J. E. T. (2011). Action-specific effects underwater. Perception, 40, 530-537. doi:10.1068/P6910

Witt, J. K., South, S. C., \& Sugovic, M. (2014). A perceiver's own abilities influence perception, even when observing others. Psychonomic Bulletin \& Review, 21, 384-389. doi:10.3758 /s13423-013-0505-1

Witt, J. K., Stefanucci, J. K., Riener, C. R., \& Proffitt, D. R. (2007). Seeing beyond the target: Environmental context affects distance perception. Perception, 36, 1752-1768. doi:10.1068/P5617

Witt, J. K., \& Sugovic, M. (2010). Performance and ease influence perceived speed. Perception, 39, 1341-1353. doi:10.1068/P6699

Witt, J. K., \& Sugovic, M. (2012). Does ease to block a ball affect perceived ball speed? Examination of alternative hypotheses. Journal of Experimental Psychology: Human Perception and Performance, 38, 1202-1214. doi:10.1037/a0026512

Witt, J. K., \& Sugovic, M. (2013a). Catching ease influences perceived speed: Evidence for action-specific effects from action-based measures. Psychonomic Bulletin \& Review, 20, 1364-1370. doi: 10.3758 /s13423-013-0448-6

Witt, J. K., \& Sugovic, M. (2013b). Response bias cannot explain actionspecific effects: Evidence from compliant and non-compliant participants. Perception, 42, 138-152. doi:10.1068/p7367

Witt, J. K., Sugovic, M., Tenhundfeld, N. T., \& King, Z. R. (in press). An action-specific effect on perception that avoids all pitfalls. Behavioral and Brain Sciences.

Witt, J. K., Sugovic, M., \& Dodd, M. D. (2016). Action-specific perception of speed is independent of attention. Attention, Perception, \& Psychophysics, 78, 880-890. doi:10.3758/s13414-015-1047-6 
Witt, J. K., Sugovic, M., \& Taylor, J. E. T. (2012). Action-specific effects in a social context: Others' abilities influence perceived speed. Journal of Experimental Psychology: Human Perception and Performance, 38, 715-725. doi:10.1037/a0026261

Witt, J. K., Taylor, J. E. T., Sugovic, M., \& Wixted, J. T. (2015). Signal detection measures cannot distinguish perceptual biases from response biases. Perception, 44, 289-300.

Witt, J. K., Tenhundfeld, N. T., \& Bielak, A. A. M. (in press). Dissociating perception from judgment in the action-specific effect of blocking ease on perceived speed. Attention, Perception, \& Psychophysics.
Wood, G., Vine, S. J., \& Wilson, M. R. (2013). The impact of visual illusions on perception, action planning, and motor performance. Attention, Perception, \& Psychophysics, 75, 830-834. doi:10.3758/s13414013-0489-y

Woods, A. J., Philbeck, J. W., \& Danoff, J. V. (2009). The various perceptions of distance: An alternative view of how effort affects distance judgments. Journal of Experimental Psychology: Human Perception and Performance, 35, 1104-1117. doi:10.1037/a0013622

Wraga, M. (1999). The role of eye height in perceiving affordances and object dimensions. Perception \& Psychophysics, 61, 490-507. doi:10.3758/BF03211968 